\title{
4-n-nonylphenol degradation by the genus Metarhizium with cytochrome P450 involvement
}

Monika Nowak ${ }^{1}$, Adrian Soboń ${ }^{2}$, Anna Litwin ${ }^{1}$, Sylwia Różalska ${ }^{1 *}$

${ }^{1}$ Department of Industrial Microbiology and Biotechnology, Faculty of Biology and Environmental Protection, University of Łódź, Banacha Street 12/16, 90-237 tódź, Poland

2Department of Microbial Genetics, Faculty of Biology and Environmental Protection, University of tódź, Banacha 12/16, 90-237, tódź, Poland

*Corresponding author: sylwia.rozalska@biol.uni.lodz.pl

Citation: Nowak M., Soboń A., Litwin A., Różalska S. 4-n-nonylphenol degradation by the genus Metarhizium with cytochrome P450 involvement. Chemosphere (2019) 220: 324-334 https://doi.org/10.1016/j.chemosphere.2018.12.114

Keywords: Metarhizium sp., nonylphenol, biodegradation pathway, cytochrome P450

Highlights:

- A novel 4-n-NP degradation pathway, distinctive for the genus Metarhizium is proposed

- Metarhizium species demonstrate differences in the way of 4-n-NP derivatives formation

- Cytochrome P450 is involved in the elimination of 4-n-NP by Metarhizium robertsii

\begin{abstract}
In this study, the ability of 4-n-nonylphenol (4-n-NP) elimination by fungal species belonging to the genus Metarhizium was investigated. The occurrence of 35 metabolites from 4-n-NP degradation was confirmed. For the first time, based on the obtained results, the 4-n-NP biodegradation pathway distinctive for the genus Metarhizium was proposed. Principal Component Analysis (PCA) indicated that despite the similar elimination pathway in all the examined Metarhizium species, there are significant differences in the kinetics of degradation of 4-n-NP. Oxidation of the terminal methyl group of the aliphatic chain leading to the formation of carboxylic acids coupled with the removal of terminal carbon is characteristic of $M$. robertsii and $M$. guizhouense, whereas metabolites with a hydroxyl group in the distal part of the nonyl chain distinguish M. lepidiotae and M. majus. Additionally, this study verified the participation of cytochrome P450 in the elimination of the xenobiotic by Metarhizium as experimentally proven for $M$. robertsii.
\end{abstract}

\section{Introduction}

Endocrine disrupting chemicals (EDCS), chiefly organic compounds, alter the endocrine system of a vertebrate by mimicking natural hormones and by blocking hormone receptors, which causes deleterious effects in humans and in animals even at trace levels (Koumaki et al., 2018; Rajendran et al., 2016; Zheng et al., 2018).

Among all EDCs, 4-nonylphenols (4-NPs) have drawn great attention because of their high estrogenic potential. Exposure of wildlife to EDCs causes multiple harmful effects such as alterations in sexual development, disorders of the homeostasis, delay in growth, and changes in the community structure of the microorganism in the soil (Chang et al., 2007; Janicki et al., 2018; Liu et al., 2017).

The ability of different fungal species to remove NPs has been demonstrated in the literature. To date, biodegradation of NPs by the nonligninolytic fungus, such as Umbelopsis isabellina (Janicki et al., 2018), Metarhizium robertsii (Różalska et al., 2015b; Szewczyk et al., 2014), Candida aquaetextoris (Vallini et al., 2001), Aspergillus strains (Krupiński et al., 2013; Yang et al., 2018), and other fungal species (Różalska et al., 2010) has been described. However, to the best of our knowledge, it has not been compared for most species belonging to the same genus. Previously, the ability of the newly isolated Metarhizium robertsii IM6519 strain in the degradation of 4-n-NP along with the formation of more than 30 derivatives and xenobiotic mineralization was described (Różalska et al., 2015b).

Fungi belonging to the genus Metarhizium are unique microorganisms with the ability to parasitize insects. They are abundantly found in the soil and have frequent contact with various anthropogenic pollutants such as NPs. These fungi are often used as biopesticides to control insect populations, and some of the strains are commercially available (Lovett and St. Leger, 2017) and they can also be exploited in the removal of xenobiotics (Szewczyk et al., 2018).

Fungal monooxygenases are involved in various metabolic processes, e.g., in the removal of xenobiotics. They have different structures, have versatile catalytic properties, and have a wide range of substrates (Durairaj et al., 2016). Moreover, monooxygenases engagement in the breakdown of nonylphenol has been also confirmed in the microsomes of 
human liver (Deng et al., 2010), Atlantic salmon (Thibaut et al., 2002), as well as in tobacco cells (Berger et al., 2005). Our study has showed that in Metarhizium sp. in the presence of the xenobiotic, cytochrome P450 (CYP450) activity increased. Additionally, CYP450 involvement in the elimination of nonylphenol by entomopathogenic fungus was confirmed. Also, for the first time, the universal biodegradation pathway within the genus Metarhizium was demonstrated.

\section{Materials and methods}

2.1. Strains, cultivation, degradation experiments, and estimation of fungal biomass

The following species of genus Metarhizium were cultured: $M$. acridum ARSEF7486, M. anisopliae ARSEF7487, M. brunneum ARSEF2107, M. globosum ARSEF2596, M. guizhouense ARSEF6238, M. lepidiotae ARSEF7412, M. majus ARSEF1914, and $M$. robertsii ARSEF727. These strains were obtained from the Collection of Entomopathogenic Fungal Cultures (ARSEF, USA). The cultures were maintained on ZT agar slants for 14 days and were inoculated in $20 \mathrm{~mL}$ Sabouraud medium (SigmaAldrich, Germany) in $100 \mathrm{~mL}$ Erlenmeyer flasks. After $1 \mathrm{~d}$ of incubation, the precultures were transferred to a fresh minimal medium at a ratio of 1:9 (Różalska et al., 2015a). The concentration of 4- $n$-NP in the culture medium was $50 \mathrm{mg} \mathrm{L}^{-1}$. Stock solution was prepared in ethanol at a concentration of 20 $\mathrm{mg} \mathrm{mL}^{-1}$. Abiotic controls (without fungal biomass) and biotic controls (without toxic substrate) were also prepared. The samples were incubated on a rotary shaker $(160 \mathrm{rpm})$ at $28^{\circ} \mathrm{C}$. For the estimation of fungal biomass and for gas chromatography-mass spectrometry (GC-MS) analyses, samples were collected at 6-hour intervals. For biomass estimation the mycelia were filtered through a Whatman filter paper number 1 (Sigma-Aldrich, Germany) and then dried at $105^{\circ} \mathrm{C}$ until a constant weight was obtained. Other chemicals and reagents were purchased from Sigma-Aldrich (Germany) unless otherwise stated.

\subsection{Quantitative analysis of 4-n-NP}

The fungal cultures were homogenized and extracted with ethyl acetate and methylene chloride (Chempur, Poland) (Różalska et al., 2015b). After evaporation to dryness under reduced pressure, solvent-free residues were dissolved in appropriate amounts of ultra-pure ethyl acetate. The substrate concentration was determined by performing GC-MS (Agilent Technologies, USA, 7890 A series). GC equipped with a mass selective (MS) detector $5975 \mathrm{C}$ and a $30 \mathrm{~m}$ HP-5 MS capillary column with an internal diameter of $250 \mu \mathrm{m}$ and film thickness of $0.25 \mu \mathrm{m}$ (Agilent Technologies, USA). The injection volume was $2 \mu \mathrm{L}$. The inlet was set to a split mode with a split ratio of 10:1 (the split flow was $10 \mathrm{~mL} \mathrm{~min}^{-1}$ ) and the temperature was maintained at $275^{\circ} \mathrm{C}$. Helium was used as the carrier gas at a constant flow rate of $1.2 \mathrm{~mL} \mathrm{~min}^{-1}$. The column temperature parameters were as follows: $100^{\circ} \mathrm{C}$ maintained for $2 \mathrm{~min}$ and then increased at a rate of $20^{\circ} \mathrm{Cmin}^{-1}$ to $300^{\circ} \mathrm{C}$ and maintained for $8 \mathrm{~min}$. The following temperature program was applied for the mass selective detector: $\mathrm{MS}$ source, $250^{\circ} \mathrm{C}$; MS quadrupole, $200{ }^{\circ} \mathrm{C}$; and selective ion monitoring (SIM) mode: target (quantifying) ion at $m / z 107$ and qualifier ion at $m / z 220$. A standard equation was generated for the quantitative analysis in the linear range from 0 to $50 \mu \mathrm{g} \mathrm{mL}^{-1} 4-n$-NP (Różalska et al., 2015b).

\subsection{Qualitative analysis}

The metabolites of 4- $n$-NP were identified according to the methods described in previous publications (Krupiński et al., 2014; Różalska et al., 2015b). Briefly, the extracts were dissolved in $1 \mathrm{~mL}$ of ethyl acetate and from this, $200 \mu \mathrm{L}$ sample was transferred into the chromatographic vial. After evaporation to dryness under the $\mathrm{N}_{2}$ gas stream, $50 \mu \mathrm{L}$ of $\mathrm{N}, \mathrm{O}$ bis(trimethylsilyl)trifluoroacetamide (BSTFA) was added and heated to $60^{\circ} \mathrm{C}$ for $60 \mathrm{~min}$. Finally, $200 \mu \mathrm{L}$ of ethyl acetate was added and GC-MS analyses were performed. The injection volume in splitless mode was set to $2 \mu \mathrm{L}$. The samples were analyzed with GC-MS at scan mode with the mass range set from 45.0 amu to $550.0 \mathrm{amu}$. The biodegradation products of 4-n-NP were identified as described previously (Różalska et al., 2015b). Moreover, the relative abundances of the metabolites were calculated and the obtained data were subjected to principal component analysis (PCA, MarkerView software version 1.2.1., AB Sciex, USA). Briefly, the orthogonal rotation (varimax) with normalization using total area sums and Pareto scaling on the data set was applied.

\subsection{Determination of CYP450 activity}

CYP450 activity was determined according to the previously published methods with adaptations for human or animal microsomes (Donato et al., 2004; Johnson et al., 2012; Zamaratskaia and Zlabek, 2009). Briefly, microsomes were isolated from the fungal biomass of all the tested Metarhizium sp. after $24 \mathrm{~h}$ of cultivation in the mineral medium with or without 4-n-NP (biotic control). The cultures were filtered through Whatman filter paper number 1 and transferred to the Eppendorf tubes containing glass beads. To each sample, $1 \mathrm{~mL}$ of buffer ( $100 \mathrm{mM}$ potassium phosphate, $\mathrm{pH}=7.5$ containing 1 mM EDTA, 1 mM DTT, 0.5 mM PMSF, 20\% glycerol) was added. Disintegration was performed on the FastPrep (MP Biomedicals, USA): speed, $4 \mathrm{~m} \mathrm{~s}^{-1}$; time, $20 \mathrm{~s}$; and cooling on ice, $1 \mathrm{~min}$. After disintegration and centrifugation at $15000 \times \mathrm{g}$ for $15 \mathrm{~min}$ at $4{ }^{\circ} \mathrm{C}$, the supernatant was transferred to an ultracentrifuge tube and centrifuged again at $105000 \times g$ for $1 \mathrm{~h} 15$ min at $4{ }^{\circ} \mathrm{C}$. The microsomal pellet was resuspended in the buffer and the microsomal protein concentrations were assayed with Bradford method using bovine serum albumin as the standard.

CYP450 activities were measured by incubating the prepared microsomes ( $100 \mu$ g of protein) in $150 \mu \mathrm{L}$ of $100 \mathrm{mM}$ potassium phosphate buffer, $\mathrm{pH}=7.5$, containing the NADPH-regenerating system $(500 \mu \mathrm{M}$ NADPH, $500 \mu \mathrm{M}$ glucose 6-phosphate and 50 
$\mathrm{U} \mathrm{mL}^{-1}$ glucose 6-phosphate dehydrogenase) and $1 \mathrm{mM}$ coumarin as the substrate. After $10 \mathrm{~min}$ of incubation, the reaction product (7-hydroxycoumarin) was measured fluorometrically at an excitation wavelength of $355 \mathrm{~nm}$ and an emission wavelength of $460 \mathrm{~nm}$ in a FLUOstar (BMG Labtech, Germany) microplate reader. In addition, a standard curve using 7-hydroxycoumarin was prepared, and the results of CYP450 activity were expressed as nanomoles of the product per mg of protein.

\subsection{CYP450 inhibition studies}

For CYP450 inhibition studies, the following procedure was adopted. Briefly, 1-aminobenzotriazole (ABT) (1 mM) dissolved in ethanol was added at $0 \mathrm{~h}$ and $6 \mathrm{~h}$ of incubation to $20 \mathrm{~mL}$ of M. robertsii ARSEF727 culture supplemented with 4-n-NP (50 $\mathrm{mg} \mathrm{L}^{-1}$ ) on the mineral medium. After $24 \mathrm{~h}$ of incubation, the samples were homogenized and extracted with ethyl acetate and methylene chloride as previously described. In addition, GC-MS qualitative analyses of the metabolites produced were performed after BSFTA derivatization.

\subsection{Data analysis}

Fungal biomass estimation and experiments of CYP450 activity were conducted in six repetitions. Sample variability is given as a standard deviation ( \pm SD). Statistical significance was investigated with the Mann-Whitney $U$ test and one-way analysis of variance (ANOVA) (Kruskal-Wallis test) using 4-n-NP as the factor on transformed data. Values at $P<0.05$ were considered as significant. The data were analyzed using Statistica 13.1 (StatSoft, USA). Qualitative data of derivatives were subjected to PCA in orthogonal rotation with normalization using total area sums and Pareto scaling. Marker View software 1.2.1. (AB Sciex, USA) was used to analyze the data.

\section{Results and discussion}

\subsection{Utilization of 4-n-NP by different species of genus Metarhizium.}

Figure 1 presents the utilization of 4-n-NP (50 mg L-1) by eight species of the genus Metarhizium. All the tested Metarhizium sp. showed the ability to remove 4-n-NP from the culture medium (see Fig. $1 \mathrm{~S}$ for additional details). The decrease in the concentration of 4-n-NP was observed after $6 \mathrm{~h}$ of incubation. Among the tested strains, $M$. globosum, $M$. acridum, $M$. guizhouense, $M$. robertsii, and $M$. anisopliae were the most effective, and after $24 \mathrm{~h}$ of incubation, about $15-30 \%$ of 4-n-NP remained in the culture extracts. At the end of the experiment, less than $5 \%$ of $4-n$-NP was detected. As compared to the abovementioned strains, M. majus and $M$. lepidiotae were less efficient in the removal of 4-n-NP, in which after $48 \mathrm{~h}$ of incubation, 39.3\% and 34,5\% (respectively) of 4-n-NP were detected in the culture medium. Kinetics of degradation of 4-nNP for M. brunneum was found to be completely different from that of the abovementioned strains. In this case, after $24 \mathrm{~h}$ of incubation, $55 \%$ of $4-n-\mathrm{NP}$ was detected, but after $48 \mathrm{~h}$ of incubation, it was below $10 \%$. The amount of $4-n$-NP in abiotic controls remained constant during this experiment.

In our previous study, we demonstrated that $M$. robertsii IM6519 can degrade and mineralize 4-n-NP (Różalska et al., $2015 b)$. The strain removed $85 \%$ of the $4-n$-NP after $24 \mathrm{~h}$ of incubation (initial concentration of $40 \mathrm{mg} \mathrm{L}^{-1}$ ) (Różalska et al., 2015b). In this study, M. robertsii ARSEF727 also removed 85\% of 4- $n$-NP (initial concentration of $50 \mathrm{mg} \mathrm{L}^{-1}$ ) (Fig. 1). This shows the similarity in both the strains of $M$. robertsii. However in this study we further show that biodegradation of this xenobiotic was found to be characteristic of the genus Metarhizium.

In the literature, there are studies describing the ability of filamentous fungi, ligninolytic and nonligninolytic, to degrade 4-

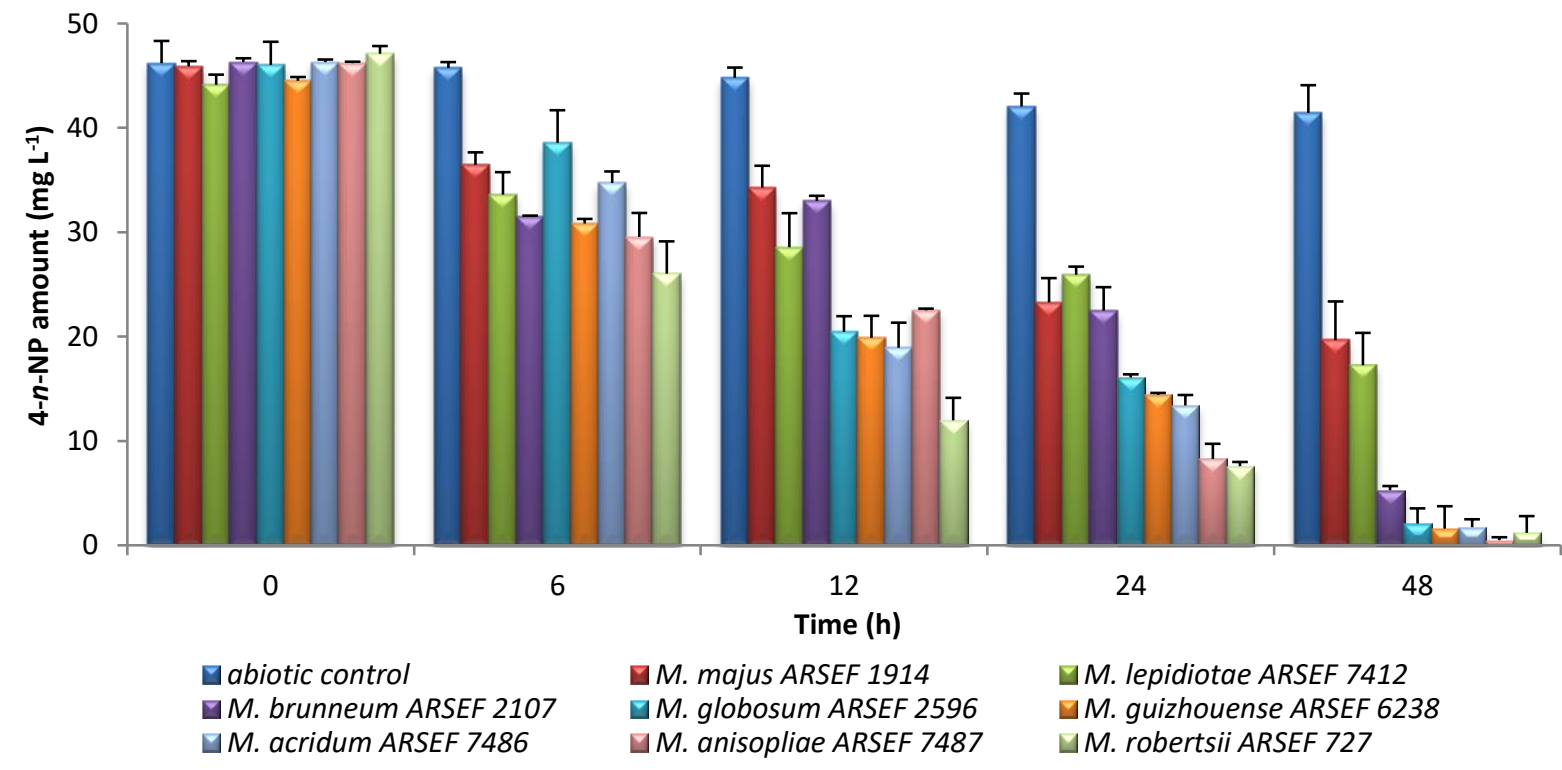

Fig. 1. 4-n-nonylphenol (4-n-NP) utilization by species belonging to the genus Metarhizium. 


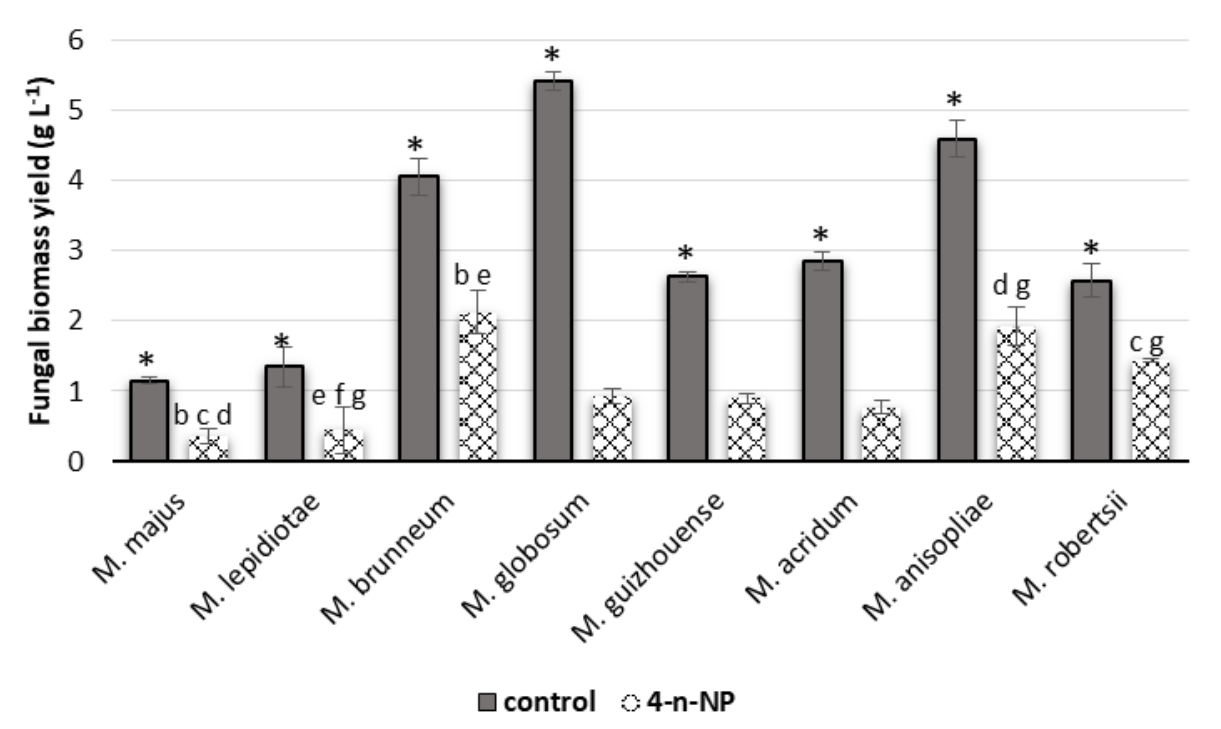

Fig. 2. 4-n-nonylphenol (4-n-NP) influence on biomass yield of Metarhizium sp. after $1 \mathrm{~d}$ of incubation. $\left({ }^{*} P<0.05-\right.$ statistically significant decrease in biomass in the sample with 4-n-NP relative to the control). Results were tested by one-way ANOVA. Statistical significance was also noticed between samples with 4-n-NP: Metarhizium majus and Metarhizium brunneum ( $\mathrm{b}, \mathrm{P}=0.000552)$, M. majus and Metarhizium robertsii (c, $\mathrm{P}=0.000760), M$. majus and Metarhizium anisopliae ( $\mathrm{d}, \mathrm{P}=0.003368)$, Metarhizium lepidiotae and $M$. brunneum $(\mathrm{e}, \mathrm{P}=0.001554), M$. lepidiotae and $M$. robertsii ( $\mathrm{f}, \mathrm{P}=0.002108)$, and $M$. lepidiotae and $M$. robertsii and $M$. anisopliae $(\mathrm{g}, \mathrm{P}=0.008625)$.

$n$-NP, but to the best of our knowledge, there are no such papers describing the degradation potential on the level of one genus. Therefore, it is very difficult to draw coherent conclusions regarding the degradation capacity within one genus because of different incubation times and various concentrations of the xenobiotics tested (Cabana et al., 2007; Cajthaml, 2014; Corvini et al., 2006).

\subsection{Biomass content of Metarhizium sp. in the presence of 4 - $n-\mathrm{NP}$}

Figure 2 shows that in the case of all the tested Metarhizium sp., the biomass content was lower in the presence of 4-n-NP than that of control samples $(P<0.05)$. The highest growth inhibition in the presence of 4-n-NP was demonstrated for M. globosum and then for M. acridum ( $83 \%$ and $73 \%$, respectively, with reference to the control) $(P<0.05)$. In $M$. majus, M. lepidiotae, and $M$. guizhouense, the biomass obtained from the samples with 4-n-NP was about $70 \%$ lower than that of the control $(P<$ 0.05). It is noteworthy that for M. majus and M. lepidiotae, the amount of biomass in biotic controls was the lowest among the tested species. For the other strains, the difference in the amount of biomass between biotic and tested samples was less visible, although statistically significant.

\subsection{Metarhizium sp. degradation pathway}

Qualitative analyses of the metabolites formed during the degradation of 4-n-NP by the eight tested species of the genus Metarhizium were based on the samples collected at five time points-at $0 \mathrm{~h}$ and after $6,12,24$, and $48 \mathrm{~h}$ of incubation. The degradation products of 4-n-NP were identified based on the characteristic fragmentation patterns described in our previous study (Różalska et al., 2015b). The data were confirmed with the NIST08 Mass Spectral Database with a probability range of 90-99\% (Tab. 1).

Figure 3 shows the proposed pathway of 4-n-NP degradation by tested Metarhizium species, which is very complex. All xenobiotic derivatives as listed in Table 1 were detected in the culture extracts of these strains. PCA was used to evaluate the complex results. Figure 4 shows PC1/PC2 scores and loading plots acquired by performing orthogonal rotation PCA, with normalization using total area sums and Pareto scaling.

The arrangement of the tested species on the PCA chart (Fig. 4) corresponds, to a large extent, with the data on the elimination of $4-n$-NP by Metarhizium sp. (Fig. 1). All the derivatives were detected in the extracts of the eight tested species suggesting that the degradation pathway of 4-n-NP is a universal type for Metarhizium sp. However, we observed significant differences in the kinetics of formation of these derivatives among the tested strains. It was found that at particular stages of xenobiotic degradation, the tested species showed the presence of derivatives of various parts of the proposed pathway of 4-n-NP degradation. Therefore, the degradation pathway was divided into four groups (groups I-IV) of derivatives, which allows for a better understanding of the individual stages of 4-n-NP degradation among the tested species. The derivatives assigned to group I possess a hydroxyl group next to the aromatic ring in the nonyl-moiety and some of them also have the second (versatile) hydroxyl group in the nonyl chain. Group II derivatives include monohydroxylated metabolites with a hydroxyl group in the distal part of the nonyl chain. The tested Metarhizium species were capable of consecutively oxidizing the terminal methyl group of the aliphatic chain, leading to the formation of carboxylic acids coupled with terminal removal of carbon. This is the most common mechanism of 4-n-NP biodegradation by microorga- 
Tab. 1. Gas chromatography-mass spectroscopy results of qualitative analysis of 4-n-nonylphenol (4-n-NP) degradation by Metarhizium sp.

\begin{tabular}{|c|c|c|c|c|c|}
\hline ID & $\begin{array}{l}\text { Retention } \\
\text { time (min) }\end{array}$ & $\begin{array}{l}\text { Compound name } \\
\text { (TMS-derivatives) }\end{array}$ & Chemical formula & $\begin{array}{l}\text { Molecular } \\
\text { mass (Da) }\end{array}$ & Mass spectrum $\mathrm{m} / \mathrm{z}$ (10 largest ions relative intensity) \\
\hline 1 & 7.520 & Phenylacetic acid, TMS & $\mathrm{C}_{11} \mathrm{H}_{16} \mathrm{O}_{2} \mathrm{Si}$ & 208.32 & $\begin{array}{l}73 \text { (99.9), } 75 \text { (34), } 91 \text { (19.7), } 164 \text { (19.7), } 193 \text { (12.5), } 45 \\
(9.9), 65(9.9), 74(9.7), 89(5.8), 90 \text { (5.7) }\end{array}$ \\
\hline 2 & 8.713 & 1-(4-hydroxyphenyl)ethanone, TMS & $\mathrm{C}_{11} \mathrm{H}_{16} \mathrm{O}_{2} \mathrm{Si}$ & 208.33 & $\begin{array}{l}193(99.9), 208(25.6), 194(16.3), 73(14.6), 151 \text { (12.9), } \\
45(10.2), 75(5), 89(7.4), 91(5.5), 195(4.8)\end{array}$ \\
\hline 3 & 9.652 & 4-Hydroxybenzoic acid, di-TMS & $\mathrm{C}_{13} \mathrm{H}_{22} \mathrm{O}_{3} \mathrm{Si}_{2}$ & 282.49 & $\begin{array}{l}267(99.9), 223(73.6), 193(58), 73(50.9), 282(24.4), \\
268(23.5), 224(16.4), 126(11.8), 194(10.3), 269(9.8)\end{array}$ \\
\hline 4 & 9.716 & $\begin{array}{l}\text { 2-(4-Hydroxyphenyl)acetic acid, } \\
\text { di-TMS }\end{array}$ & $\mathrm{C}_{14} \mathrm{H}_{24} \mathrm{O}_{3} \mathrm{Si}_{2}$ & 296.52 & $\begin{array}{l}73 \text { (99.9), } 179 \text { (30.1), } 75 \text { (16.1), } 164 \text { (15.8), } 252 \text { (15.7), } \\
296 \text { (915.3), } 281(14.7), 74(9), 45(8.5), 163(6.6)\end{array}$ \\
\hline 5 & 10.411 & $\begin{array}{l}\text { 3-(4-Hydroxyphenyl)propanoic } \\
\text { acid, di-TMS }\end{array}$ & $\mathrm{C}_{15} \mathrm{H}_{26} \mathrm{O}_{3} \mathrm{Si}_{2}$ & 310.54 & $\begin{array}{l}179(99.9), 192(63.3), 73(29.3), 235(24.6), 310(22.4) \text {, } \\
177(17.4), 193(16.9), 180(15.6), 75(13.1), 295 \text { (7.2) }\end{array}$ \\
\hline 6 & 10.74 & $\begin{array}{l}\text { 3,4-Dihydroxybenzoic acid, } \\
\text { tri-TMS }\end{array}$ & $\mathrm{C}_{16} \mathrm{H}_{30} \mathrm{O}_{4} \mathrm{Si}_{3}$ & 370.67 & $\begin{array}{l}193(99.9), 370(55.7), 73(48.9), 355(29.3), 311 \text { (20.1), } \\
371(18.5), 194 \text { (15.2), } 281(10.9), 223 \text { (9.7), } 356 \text { (9.4) }\end{array}$ \\
\hline 7 & 10.798 & (3,4-Dihydroxyphenyl)acetic acid, tri-TMS & $\mathrm{C}_{17} \mathrm{H}_{32} \mathrm{O}_{4} \mathrm{Si}_{3}$ & 384.69 & $\begin{array}{l}73(99.9), 179(60.9), 384(55.5), 267(49.7), 385(19.3) \text {, } \\
237(15.8), 75(13.9), 268(13.7), 45(9.1), 369 \text { (9.1) }\end{array}$ \\
\hline 8 & 10.962 & $\begin{array}{l}\text { 4-(4-Hydroxyphenyl)butanoic acid, } \\
\text { di-TMS }\end{array}$ & $\mathrm{C}_{16} \mathrm{H}_{28} \mathrm{O}_{3} \mathrm{Si}_{2}$ & 324.57 & $\begin{array}{l}192(99.9), 73(24.1), 193(18.6), 179(17.9), 309 \text { (16.2), } \\
324(15.7), 177(15.4), 75(14.7), 147(7.6), 194(5.1)\end{array}$ \\
\hline 9 & 11.249 & 4-n-Nonylphenol, TMS & $\mathrm{C}_{18} \mathrm{H}_{32} \mathrm{OSi}$ & 292.54 & $\begin{array}{l}179(99.9) 292(39) 180(21.8) 73(16.6), 293(10.6) 181 \\
(6.6) 277(5.9) 163(4.0), 165(3.7) 149(3.3)\end{array}$ \\
\hline 10 & 11.346 & $\begin{array}{l}\text { (2E)-3-(4-Hydroxyphenyl)prop-2-enoic acid, di- } \\
\text { TMS }\end{array}$ & $\mathrm{C}_{15} \mathrm{H}_{24} \mathrm{O}_{3} \mathrm{Si}_{2}$ & 308.52 & $\begin{array}{l}293(99.9), 219(85.2), 308(80), 73(55.2), 249(48.8), \\
294(25.8), 309(21.4), 220(18.9), 179(14.8), 250(10.6)\end{array}$ \\
\hline 11 & 11.395 & 3-(3,4-Dihydroxyphenyl)propanoic acid, tri-TMS & $\mathrm{C}_{18} \mathrm{H}_{34} \mathrm{O}_{4} \mathrm{Si}_{3}$ & 398.71 & $\begin{array}{l}179(99.9), 398 \text { (91.5), } 267(55.2), 73(51.9), 399(31.3), \\
280(17.5), 180(14.6) 400 \text { (14.2), } 268(13.6), 383(12.1)\end{array}$ \\
\hline 12 & 11.464 & 5-(4-Hydroxyphenyl)pentanoic acid, di-TMS & $\mathrm{C}_{17} \mathrm{H}_{30} \mathrm{O}_{3} \mathrm{Si}_{2}$ & 338.60 & $\begin{array}{l}179 \text { (99.9), } 73(43.4), 75(24.1), 338(23.8), 192(23.2), \\
323(19.3), 180(16.3), 149(15.9), 205(13.4), 206(7.9)\end{array}$ \\
\hline 13 & 11.858 & 4-(3,4-Dihydroxyphenyl)butanoic acid, tri-TMS & $\mathrm{C}_{19} \mathrm{H}_{36} \mathrm{O}_{4} \mathrm{Si}_{3}$ & 412.74 & $\begin{array}{l}412 \text { (99.9), } 280 \text { (99.5), } 73 \text { (78.1), } 267(37.7), 413(35), \\
235(29.7), 281(26.8), 179(25.7), 397(18.3), 75(18)\end{array}$ \\
\hline 14 & 11.925 & $\begin{array}{l}\text { 4-Hydroxy-4-(4-hydroxyphenyl)butanoic acid, tri- } \\
\text { TMS }\end{array}$ & $\mathrm{C}_{19} \mathrm{H}_{36} \mathrm{O}_{4} \mathrm{Si}_{3}$ & 412.74 & $\begin{array}{l}412(99.9), 73(81.2), 267(60.4), 179(47.9), 413(37.2), \\
268(16.3), 414(16.1), 233(15.5), 75(10.3), 74(7.2)\end{array}$ \\
\hline 15 & 11.965 & 6-(4-Hydroxyphenyl)hexanoic acid, di-TMS & $\mathrm{C}_{18} \mathrm{H}_{32} \mathrm{O}_{3} \mathrm{Si}_{2}$ & 352.63 & $\begin{array}{l}179(99.9) 352(31.7) 73 \text { (31) } 180 \text { (16.1) } 337 \text { (14.9) } 75 \\
(14.7), 353(9.4) 253(6.9) 181(4.6), 177(4.5)\end{array}$ \\
\hline 16 & 12.127 & 4-(1-Hydroxynonyl)phenol, di-TMS & $\mathrm{C}_{21} \mathrm{H}_{40} \mathrm{O}_{2} \mathrm{Si}_{2}$ & 380.71 & $\begin{array}{l}380(99.9), 267(82), 73(76.7), 179(37.5), 381 \text { (34.8), } \\
268(23.3), 382(12.8), 269(8.9), 365(7.9), 180 \text { (6.9) }\end{array}$ \\
\hline 17 & 12.266 & 8-(4-Hydroxyphenyl)nonanal, TMS & $\mathrm{C}_{18} \mathrm{H}_{30} \mathrm{O}_{2} \mathrm{Si}$ & 306.51 & $\begin{array}{l}179(99.9), 306(26.2), 73(22), 180(16.4), 43(8.8), 181 \\
(7.5), 307(6.6), 163(3.8), 75(3.7), 149(3.5)\end{array}$ \\
\hline 18 & 12.237 & 7-(4-Hydroxyphenyl)nonanal, TMS & $\mathrm{C}_{18} \mathrm{H}_{30} \mathrm{O}_{2} \mathrm{Si}$ & 306.51 & $\begin{array}{l}179(99.9), 306(26.4), 73(23), 180(16), 181(7.5), 57 \\
(7.3), 307(6.5), 192(5.7), 75(4.1), 177(4)\end{array}$ \\
\hline 19 & 12.285 & $\begin{array}{l}\text { (2E)-3-(3,4-Dihydroxyphenyl)prop-2-enoic acid, } \\
\text { tri-TMS }\end{array}$ & $\mathrm{C}_{18} \mathrm{H}_{32} \mathrm{O}_{4} \mathrm{Si}_{3}$ & 396.70 & $\begin{array}{l}219(99.9), 73(83.7), 396(75), 397(27.1), 381(19), 191 \\
(17.3), 220(17.2), 218(15.2), 179(14.9), 398(12.3)\end{array}$ \\
\hline 20 & 12.316 & 5-(3,4-Dihydroxyphenyl)pentanoic acid, tri-TMS & $\mathrm{C}_{20} \mathrm{H}_{38} \mathrm{O}_{4} \mathrm{Si}_{3}$ & 426.76 & $\begin{array}{l}426(99.9), 73(94.2), 267(77.7), 427(37), 205(31.7), 75 \\
(23), 268(21), 411(20.9), 179(20.3), 428(16.9)\end{array}$ \\
\hline 21 & 12.373 & $\begin{array}{l}\text { 5-Hydroxy-5-(4-hydroxyphenyl)pentanoic acid, } \\
\text { tri-TMS }\end{array}$ & $\mathrm{C}_{20} \mathrm{H}_{38} \mathrm{O}_{4} \mathrm{Si}_{3}$ & 426.76 & $\begin{array}{l}73 \text { (99.9), } 426 \text { (80.6), } 267(51.4), 179(47.9), 427 \text { (31.7), } \\
75(19.9), 268(15), 253(14.9), 428(14), 147 \text { (6.1) }\end{array}$ \\
\hline 22 & 12.373 & 4-(6-Hydroxynonyl)phenol, di-TMS & $\mathrm{C}_{21} \mathrm{H}_{40} \mathrm{O}_{2} \mathrm{Si}_{2}$ & 380.71 & $\begin{array}{l}73 \text { (99.9), } 179 \text { (90.2), } 290 \text { (67.8), } 145 \text { (58.9), } 205 \text { (57.1), } \\
75 \text { (31), } 291 \text { (17.2), } 192 \text { (15.5), } 180 \text { (15.1), } 206 \text { (11.5) }\end{array}$ \\
\hline 23 & 12.416 & 7-(4-Hydroxyphenyl)heptanoic acid, di-TMS & $\mathrm{C}_{19} \mathrm{H}_{34} \mathrm{O}_{3} \mathrm{Si}_{2}$ & 366.65 & $\begin{array}{l}179(99.9), 73(41.9), 366(28), 75(17.6), 180(16.2), 351 \\
(10.4), 367(8.8), 253(6.6), 181(5.1), 177(5)\end{array}$ \\
\hline 24 & 12.523 & 4-(7-Hydroxynonyl)phenol, di-TMS & $\mathrm{C}_{21} \mathrm{H}_{40} \mathrm{O}_{2} \mathrm{Si}_{2}$ & 380.71 & $\begin{array}{l}179(99.9), 73(85.7), 131(84.2), 290(51.8), 205(34.4), \\
75(24.7), 351(20.5), 380(19.6), 180(16.5), 291(13)\end{array}$ \\
\hline 25 & 12.588 & 4-(8-Hydroxynonyl)phenol, di-TMS & $\mathrm{C}_{21} \mathrm{H}_{40} \mathrm{O}_{2} \mathrm{Si}_{2}$ & 380.71 & $\begin{array}{l}179(99.9), 117(97.3), 73(76.1), 290(30), 75(27.8), 380 \\
(26.2), 205(19.2), 180(16.8), 118(10.7), 365(9.2)\end{array}$ \\
\hline 26 & 12.753 & $\begin{array}{l}\text { 6-Hydroxy-6-(4-hydroxyphenyl)hexanoic acid, tri- } \\
\text { TMS }\end{array}$ & $\mathrm{C}_{21} \mathrm{H}_{40} \mathrm{O}_{4} \mathrm{Si}_{3}$ & 440.79 & $\begin{array}{l}73 \text { (99.9), } 440 \text { (59.3), } 179 \text { (49.8), } 267 \text { (45.4), } 75 \text { (29.4), } \\
441 \text { (22.9), } 197(14.9), 268(12.6), 442(10.1), 180(7.9)\end{array}$ \\
\hline 27 & 12.796 & 6-(3,4-Dihydroxypheny))hexanoic acid, tri-TMS & $\mathrm{C}_{21} \mathrm{H}_{40} \mathrm{O}_{4} \mathrm{Si}_{3}$ & 440.79 & $\begin{array}{l}73(99.9), 440(99.7), 267(80), 179(46.6) 441(40), 268 \\
(21.6), 75(20.1), 253(18.8), 442(18), 87(14.4) 269(8.3)\end{array}$ \\
\hline 28 & 12.903 & $\begin{array}{l}\text { (4-Hydroxyphenyl)octanoic acid, } \\
\text { di-TMS }\end{array}$ & $\mathrm{C}_{20} \mathrm{H}_{36} \mathrm{O}_{3} \mathrm{Si}_{2}$ & 380.66 & $\begin{array}{l}179(99.9), 73(59.2), 380(28.7), 180(16.7), 75(12.4), \\
381(9.9), 253(8.2), 103(6.8), 181(6.5), 147(6.1)\end{array}$ \\
\hline 29 & 13.104 & 4-(1,6-Dihydroxynonyl)phenol, tri-TMS & $\mathrm{C}_{24} \mathrm{H}_{48} \mathrm{O}_{3} \mathrm{Si}_{3}$ & 468.89 & $\begin{array}{l}73 \text { (99.9), } 468(32.5), 179(29.1), 267(28.3), 145(27.2), \\
75(20.7), 469(13.7), 378(12), 293(10.3), 268(8.3)\end{array}$ \\
\hline 30 & 13.169 & $\begin{array}{l}\text { 7-Hydroxy-7-(4-hydroxyphenyl)heptanoic acid, } \\
\text { tri-TMS }\end{array}$ & $\mathrm{C}_{22} \mathrm{H}_{42} \mathrm{O}_{4} \mathrm{Si}_{3}$ & 454.82 & $\begin{array}{l}454(99.9), 73(81.5), 267(73.6), 179(57.6), 455(39.4), \\
268(20.4), 75(19.5), 439(19.5), 456(17.9), 180 \text { (9.3) }\end{array}$ \\
\hline 31 & 13.247 & 4-(1,7-Dihydroxynonyl)phenol, tri-TMS & $\mathrm{C}_{24} \mathrm{H}_{48} \mathrm{O}_{3} \mathrm{Si}_{3}$ & 468.89 & $\begin{array}{l}73 \text { (99.9), } 468(57.7), 267(41), 131(40.7), 179(28.7), \\
469(23.7), 75(19), 268(10.9), 253(10.4), 439(10.3)\end{array}$ \\
\hline
\end{tabular}




\begin{tabular}{|c|c|c|c|c|c|}
\hline 32 & 13.283 & 9-(4-Hydroxyphenyl)nonanoic acid, di-TMS & $\mathrm{C}_{21} \mathrm{H}_{38} \mathrm{O}_{3} \mathrm{Si}_{2}$ & 394.69 & $\begin{array}{l}179(99.9), 73(41.9), 394(28), 180(16.5), 75(16), 379 \\
(11.5), 395(9.2), 181(5.2), 177(4.6), 253(4.6)\end{array}$ \\
\hline 33 & 13.311 & 4-(1,8-Dihydroxynonyl)phenol, tri-TMS & $\mathrm{C}_{24} \mathrm{H}_{48} \mathrm{O}_{3} \mathrm{Si}_{3}$ & 468.89 & $\begin{array}{l}73(99.9), 468(75.3), 117(59), 267(48.6), 179(32), 469 \\
(31.9), 75(22.7), 268(21.8), 211(18), 253(15.1)\end{array}$ \\
\hline 34 & 13.605 & 4-(1,5-Dihydroxynonyl)phenol, tri-TMS & $\mathrm{C}_{24} \mathrm{H}_{48} \mathrm{O}_{3} \mathrm{Si}_{3}$ & 468.89 & $\begin{array}{l}73(99.9), 468(76.7), 267(41.8), 179(35.9), 469(31), 75 \\
(25.3), 470(14.5), 411(12.3), 268(11.6), 221(10.6)\end{array}$ \\
\hline 35 & 13.97 & $\begin{array}{l}\text { 9-Hydroxy-9-(4-hydroxyphenyl)nonanoic acid, tri- } \\
\text { TMS }\end{array}$ & $\mathrm{C}_{24} \mathrm{H}_{46} \mathrm{O}_{4} \mathrm{Si}_{3}$ & 482.27 & $\begin{array}{l}73(99.9), 482(88.9), 267(54), 179(49.4), 483(36.9), 75 \\
(22.8), 484(18.1), 467(18), 268(14.9), 74(9.2)\end{array}$ \\
\hline
\end{tabular}

nisms (group III derivatives) (Krupiński et al., 2013; Rajendran et al., 2016; Vallini et al., 2001). Group (IV) derivatives are formed by the hydroxylation of the aromatic ring, and they are probably formed from the derivatives belonging to group III. It was observed that each of the tested species showed a preference for the degradation of 4-n-NP to a particular group of derivatives.

Based on the results from the PCA analysis, at 6, 12, and 24 h of incubation, a pronounced similarity between $M$. guizhouense and $M$. robertsii strains was observed in the formation of derivatives of 4-n-NP degradation (Fig. 4). The trend analysis of product formation revealed that derivatives belonging to groups III and IV were definitely predominant in $M$. guizhouense and $M$. robertsii culture extracts. In fact, all the derivatives belonging to group III were detected after $6 \mathrm{~h}$ of incubation. The derivatives 9-(4-Hydroxyphenyl)nonanoic acid, di-trimethylsilyl (TMS) (32) and (4-Hydroxyphenyl)octanoic acid, di-TMS (28) from the initial part of the pathway were detected at high levels. Derivatives of the end of the route for group III such as 1-(4-Hydroxyphenyl)ethanone, TMS (2); 4Hydroxybenzoic acid, di-TMS (3); 2-(4-Hydroxyphenyl)acetic acid, di-TMS (4); and (2E)-3-(4-Hydroxyphenyl)prop-2-enoic acid, di-TMS (10) were detected as soon as after $6 \mathrm{~h}$ incubation and consistently appeared at high levels at subsequent incubation times. Their content was the lowest at $24 \mathrm{~h}$ of incubation. This might be due to the fact that after $24 \mathrm{~h}$ of incubation, only $5 \%$ of the substrate remained in the culture medium.

In M. guizhouense cultures, all derivatives belonging to group IV (with hydroxylation in the aromatic ring) were detected at very high levels as soon as after $6 \mathrm{~h}$ of incubation. This indicates fast kinetics of degradation by this strain. In $M$. robertsii, these derivatives were also detected but at lower levels (Fig. 4A). 6(3,4-Dihydroxyphenyl)hexanoic acid, tri-TMS (27), derived from 6-(4-Hydroxyphenyl)hexanoic acid, di-TMS (15) (located in the middle of the route of group III) was also detected at a very high level. $\ln M$. robertsii, at $6 \mathrm{~h}$ of incubation, the decomposition of metabolites belonging to group III was found to be initiated, which suggested its lower kinetics of 4-n-NP degradation than that observed for $M$. guizhouense. At 12 and $24 \mathrm{~h}$ of incubation, the percentage of derivatives belonging to group IV remained at a similar high levels in both $M$. guizhouense and $M$. robertsii. These species also exhibited the degradation of 4-n-NP to group I metabolites (a hydroxyl group next to the aromatic ring in the nonyl-moiety or/and the versatile second hydroxylation in the nonyl chain). Derivatives such as 4-(1,5Dihydroxynonyl)phenol, tri-TMS (34) or 4-(1,8Dihydroxynonyl)phenol, tri-TMS (33) and also 4-(1-
Hydroxynonyl)phenol, di-TMS (16) (with a hydroxyl group alone next to the aromatic ring), and their degradation metabolites, e.g., 5-Hydroxy-5-(4-hydroxyphenyl)pentanoic acid, tri-TMS (21) and 4-Hydroxy-4-(4-hydroxyphenyl)butanoic acid, tri-TMS (14) were detected as soon as after $6 \mathrm{~h}$ of incubation. In the following periods of incubation, these derivatives were detected as well, but differences were observed in their mutual ratio. In the case of $M$. guizhouense and $M$. robertsii, the following metabolites belonging to group II were detected at very low levels at 6,12 , and $24 \mathrm{~h}$ of incubation: 7-(4-Hydroxyphenyl)nonanal, TMS (18) formed from 4-(7-Hydroxynonyl)phenol, di-TMS (24) at $6 \mathrm{~h}$ of incubation and 8-(4-Hydroxyphenyl)nonanal, TMS (17) formed from 4-(8-Hydroxynonyl)phenol, di-TMS (25) at $12 \mathrm{~h}$ of incubation. There is a possibility that these strains degraded 4$n$-NP into derivatives belonging to group II already at the beginning of the incubation; therefore, at later periods of incubation, there was a low level of derivatives belonging this group. This part of the pathway was not dominant for these two strains. At $24 \mathrm{~h}$ of incubation, the derivatives belonging to group II were not detected for $M$. guizhouense and $M$. robertsii. $M$. lepidiotae and $M$. majus exhibited large similarities in the degradation of 4-n-NP (Fig. 4). The trend analyses of the nascent compounds revealed that group II of the pathway was definitely the main degradation route for these strains, however, $M$. lepidiotae showed the presence of more derivatives than $M$. majus in their culture extracts. At $6 \mathrm{~h}$ of incubation, the efficiency of 4-n-NP degradation in these two strains was at the lowest level among all tested species (Fig. 1). However, in M. lepidiotae, the derivatives with hydroxylation at the C2-C4 alkyl side-chain of 4-n-NP (group II), i.e., (8Hydroxynonyl)phenol, di-TMS (25); 4-(7-Hydroxynonyl)phenol, di-TMS (24); and 4-(6-Hydroxynonyl)phenol, di-TMS (22) were detected at levels of $40-60 \%$, whereas in $M$. majus, they were detected at levels of $15-25 \%$. The percentage of these derivatives increased up to $60-100 \%$ at $12 \mathrm{~h}$ of incubation. In M. lepidiotae, at 6 and $12 \mathrm{~h}$ of incubation, the derivatives with alkyl-chain hydroxylation next to the aromatic ring (group I) were detected, such as 4-(1,8-Dihydroxynonyl)phenol, tri-TMS (33); 4-(1,7-Dihydroxynonyl)phenol, tri-TMS (31); and 4-(1Hydroxy-nonyl)phenol, di-TMS (16) as well as derivatives of the beginning of the path for group III, such as 9-(4Hydroxyphenyl)nonanoic acid, di-TMS (32) and (4Hydroxyphenyl)octanoic acid, di-TMS (28). However, in $M$. majus, the formation of these metabolites began as late as after $24 \mathrm{~h}$ of incubation. Among M. majus and M. lepidiotae, $M$. 


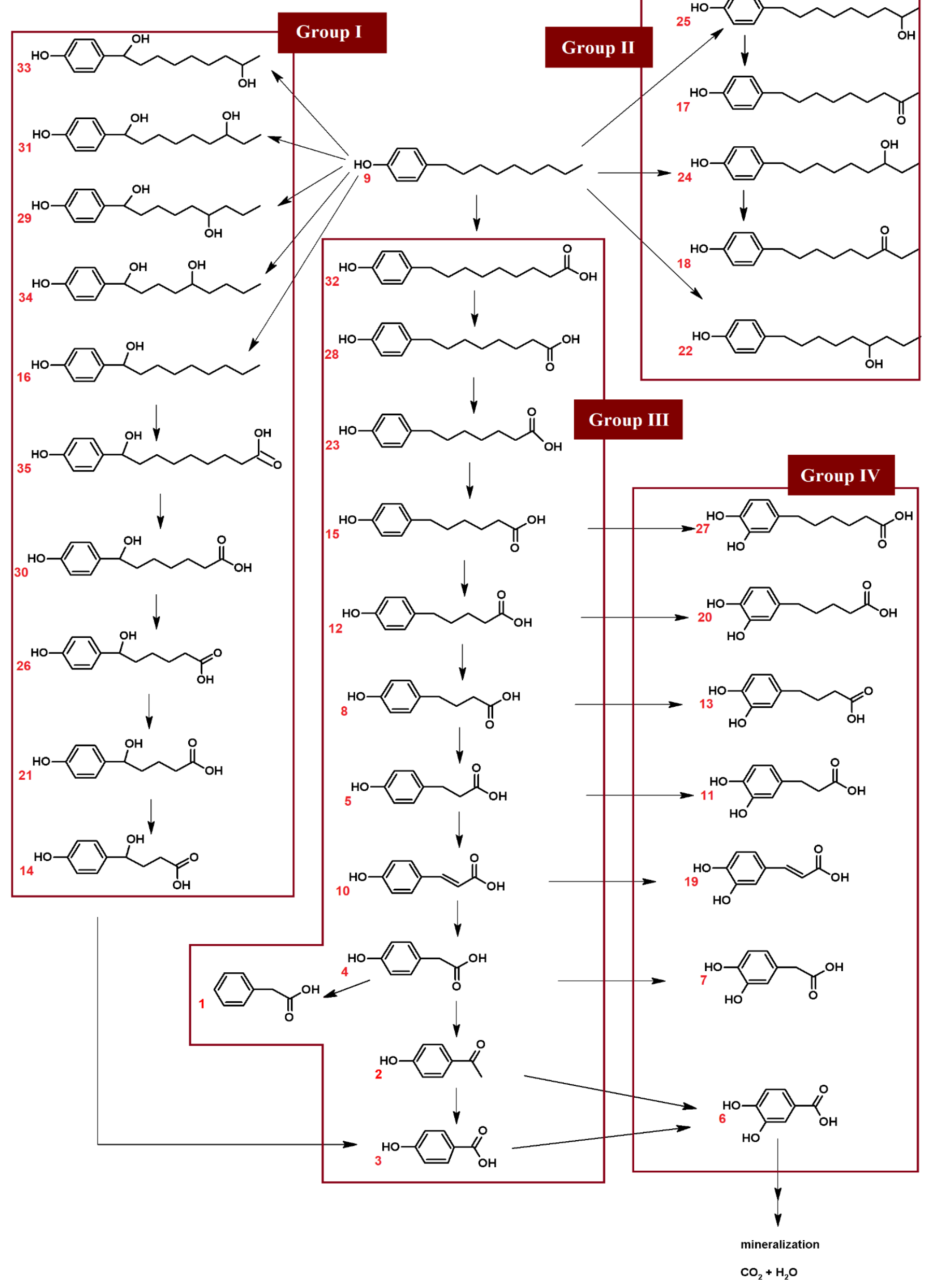

Fig. 3. Proposed 4-n-nonylphenol (4-n-NP) degradation pathway by tested species of the genus Metarhizium with division into four groups (I-IV) of derivatives. The red numbers refer to the metabolites shown in Table 1 (see text for details). (For interpretation of the references to color in this figure legend, the reader is referred to the Web version of this article.) 

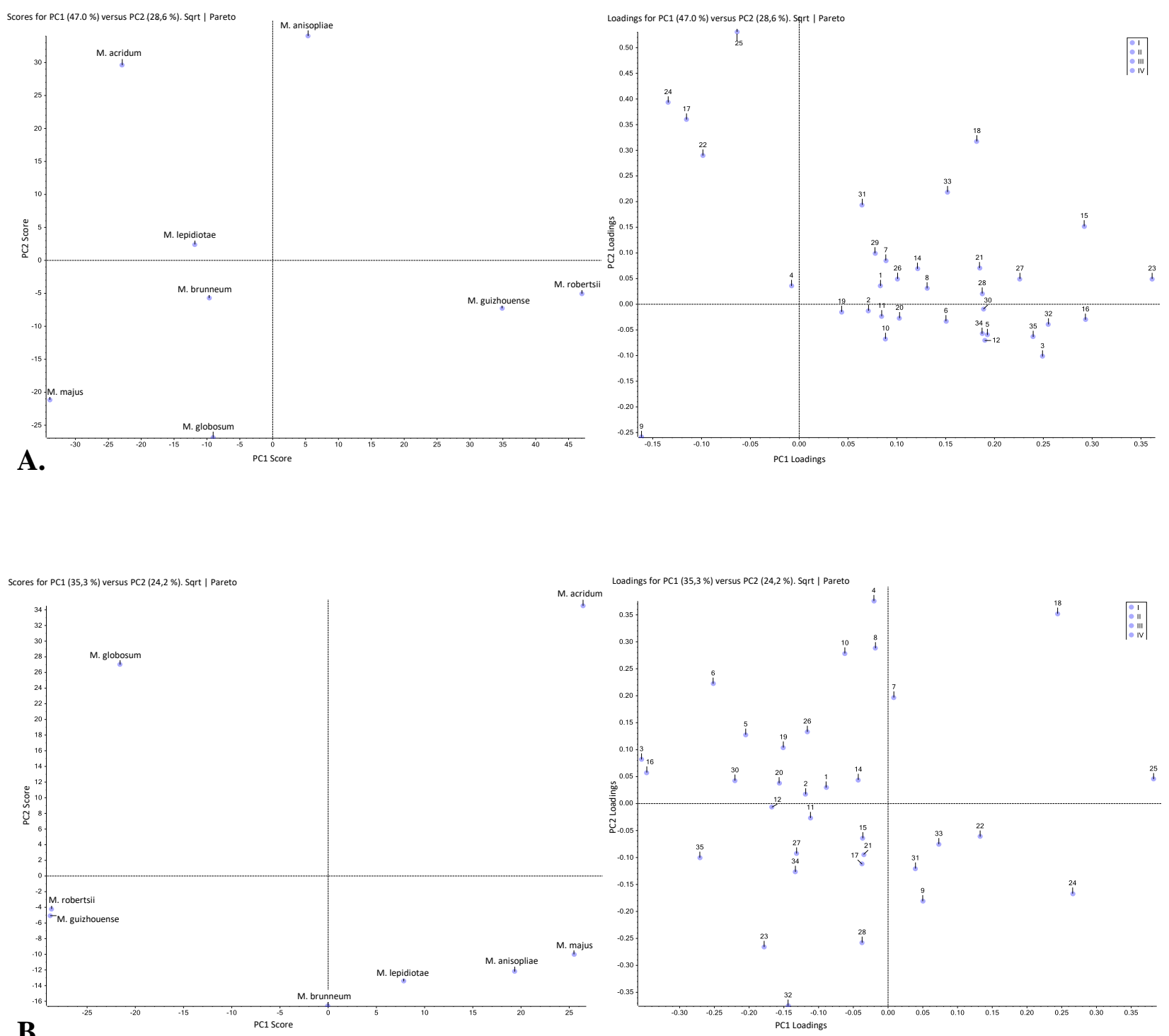

B.
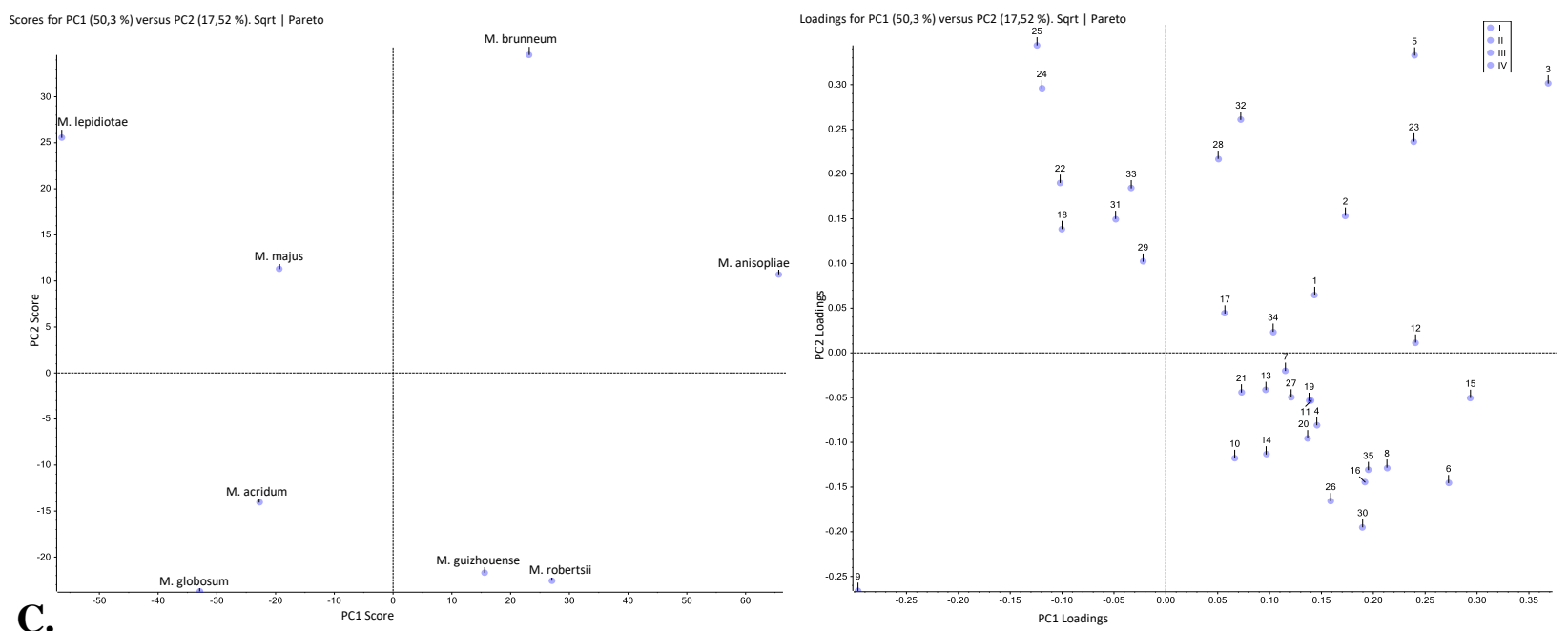

Fig. 4. Results of principal component analysis (PCA) on the 4- $n$-nonylphenol (4- $n$-NP) metabolism by the eight species from genus Metarhizium . On the right-PC1 against PC2 loadings chart; on the left-PC1 against PC2 scores chart. A. PCA chart at $6 \mathrm{~h}$ of incubation. B. PCA chart at $12 \mathrm{~h}$ of incubation. C. PCA chart at $24 \mathrm{~h}$ of incubation (see Supplementary material for additional details-Fig. 3S-5S). 


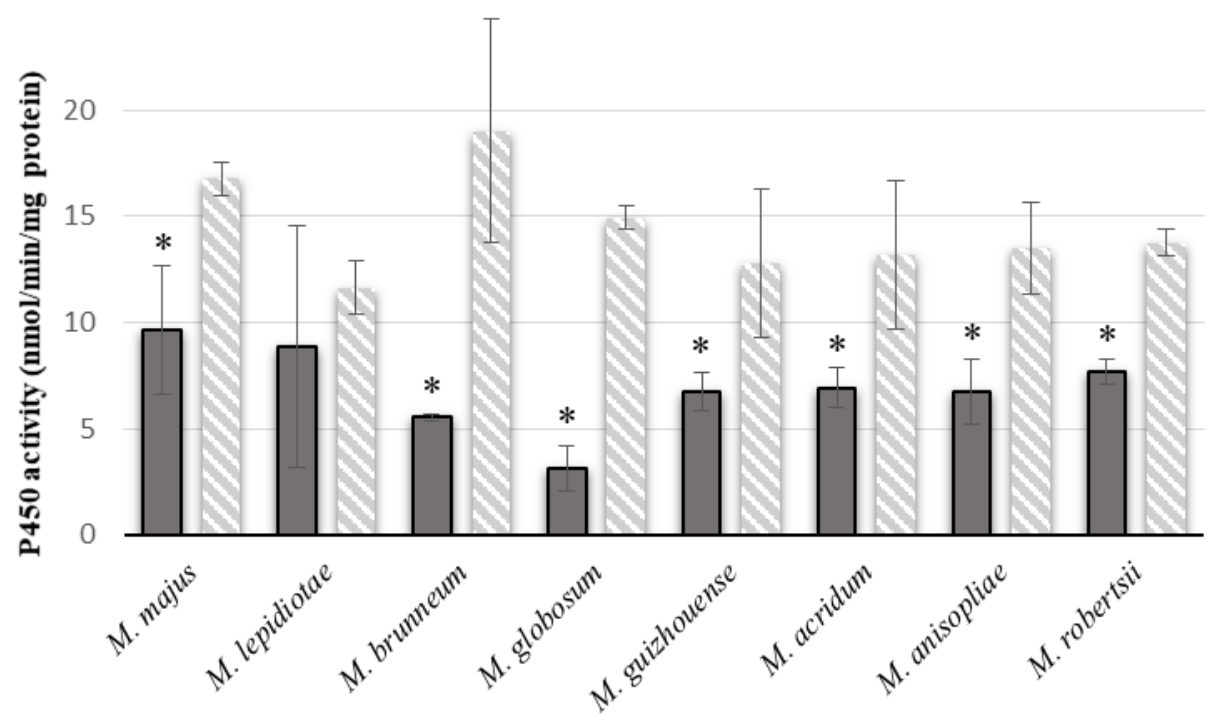

Fig. 5. Cytochrome P450 activity in microsomes of Metarhizium sp. in the absence (control) and in the presence of 4-n-nonylphenol (4-n-NP) $\left({ }^{*} P<0.05-a\right.$ statistically significant increase in cytochrome $\mathrm{P} 450$ activity in the sample with 4-n-NP relative to the control).

lepidiotae degraded 4-n-NP with higher efficiency than that of M. majus at the end of incubation (Fig. 1), although the way of derivatives formation in both strains was similar. It is noteworthy that $M$. majus and $M$. lepidiotae were the slowest growing species within the genus Metarhizium (Fig. 2).

M. globosum is presented as a separate issue, due to the lack of significant similarity with the other Metarhizium species. In this strain, derivatives belonging to group III dominated throughout the incubation period. At $6 \mathrm{~h}$ of incubation, 4-n-NP degradation was less efficient compared to the other strains (Fig. 1). The trend analysis showed that the breakthrough of the degradation process of 4-n-NP for M. globosum occurred at 12 $h$ of incubation. The amount of derivatives belonging to group III, in particular, to those from the end of the path, was at the highest level. In addition, all derivatives belonging to group IV (6, $7,11,19,20,27)$ with aromatic ring hydroxylation were detected. At $12 \mathrm{~h}$ of incubation, a high percentage of derivatives with alkyl-chain hydroxylation next to the aromatic ring (group 1), in particular 4-(1-Hydroxynonyl)phenol, di-TMS (16); 6Hydroxy-6-(4-hydroxyphenyl)hexanoic acid, tri-TMS (26); and 4-Hydroxy-4-(4-hydroxyphenyl)butanoic acid, tri-TMS (14) was detected. After $24 \mathrm{~h}$ of incubation, the kinetics of 4-n-NP degradation decreased and there was no distinctive derivative detected. The very low content of metabolites from group II throughout the incubation period was found to be distinctive for this strain. M. brunneum showed some interesting results. The dominant products of 4-n-NP degradation for this strain were metabolites belonging to group III, similar to $M$. globosum. However, $M$. brunneum definitely differed in the kinetics of 4-n-NP degradation. After 6 and $12 \mathrm{~h}$ of incubation, the derivatives of the initial part of the path of group III were detected, such as 9-(4-Hydroxyphenyl)nonanoic acid, di-TMS (32) and (4-Hydroxyphenyl)octanoic acid, di-TMS (28). In contrast to $M$. globosum, in $M$. brunneum, the degradation of 4-n-NP to derivatives of the end of the path for group III began as late as after $24 \mathrm{~h}$ of incubation and metabolites such as Phenylacetic acid, TMS (1); 4-Hydroxybenzoic acid, di-TMS (3); and 3-(4-Hydroxyphenyl)propanoic acid, di-TMS (5) were detected at very high levels. Derivatives belonging to groups I, II, and IV were also detected but at very low levels.

$M$. acridum and $M$. anisopliae were found to be similar in the kinetics of formation of 4-n-NP derivatives at $6 h$ of incubation. The trend analyses revealed that for both these strains, hydroxylation in the C2-C4 alkyl side-chain of 4-n-NP (group II) predominated. In $M$. anisopliae, high levels of 4-(8Hydroxynonyl)phenol, di-TMS (25); 4-(7-Hydroxynonyl)phenol, di-TMS (24); and 4-(6-Hydroxynonyl)phenol, di-TMS (22) and low levels of 8-(4-Hydroxyphenyl)nonanal, TMS (17) and 7-(4Hydroxyphenyl)nonanal, TMS (18) were detected. M. acridum showed contrasting results. Most likely, in $M$. acridum, the metabolites: 4-(8-Hydroxynonyl)phenol, di-TMS (25) to 8-(4Hydroxyphenyl)nonanal, TMS (17) and 4-(7Hydroxynonyl)phenol, di-TMS (24) to 7-(4Hydroxyphenyl)nonanal, TMS (18) were detected earlier than in $M$. anisopliae. Derivatives belonging to group III were also detected, but differentiation between $M$. acridum and $M$. anisopliae occurred with reference to derivatives with a hydroxyl group next to the aromatic ring in the nonyl-moiety or/and the versatile second hydroxylation in the nonyl chain (I group). In $M$. acridum, derivatives, such as $4-(1,8-$ Dihydroxynonyl)phenol, tri-TMS (33) and 4-(1,7Dihydroxynonyl)phenol, tri-TMS (31) were detected at very low levels (below 20\%). However, in $M$. anisopliae, these derivatives including the others, e.g., 4-(1Hydroxynonyl)phenol, di-TMS (16) and 5-Hydroxy-5-(4hydroxyphenyl)pentanoic acid, tri-TMS (21) were dominant (55-100\%). A significant difference between these strains was observed at $12 \mathrm{~h}$ of incubation (Fig. 4B). Only metabolites belonging to group II were found to be similar. $\ln M$. anisopliae, the degradation of 4-n-NP occurred mainly in the part of the pathway with hydroxylation next to the aromatic ring in the nonyl-moiety or/and the versatile second hydroxylation in nonyl chain (I group), whereas in M. acridum, the degradation was observed mainly in the part of the pathway with carboxylic 
Tab. 2. Gas chromatography-mass spectroscopy results of qualitative analysis of 4- $n$-nonylphenol (4-n-NP) degradation by Metarhizium sp.

\begin{tabular}{|c|c|c|c|c|c|}
\hline $\begin{array}{l}\text { Group of } \\
\text { derivatives }\end{array}$ & ID & $\begin{array}{l}\text { Compound name } \\
\text { (TMS-derivative) }\end{array}$ & $\begin{array}{l}\text { Samples without } \\
\text { addition of ABT }\end{array}$ & $\begin{array}{l}\text { Samples with addition of } \\
\text { ABT at Oh of incubation }\end{array}$ & $\begin{array}{l}\text { Samples with addition of } \\
\text { ABT after } 6 \text { h of } \\
\text { incubation }\end{array}$ \\
\hline \multirow{4}{*}{ I } & 16 & 4-(1-hydroxynonyl)phenol, di-TMS & $\checkmark$ & $x$ & $\checkmark$ \\
\hline & 26 & 6-hydroxy-6-(4-hydroxyphenyl) hexanoic acid, tri-TMS & $\checkmark$ & $x$ & $\checkmark$ \\
\hline & 30 & 7-hydroxy-7-(4-hydroxyphenyl) heptanoic acid, tri-TMS & $\checkmark$ & $x$ & $\checkmark$ \\
\hline & 35 & 9-Hydroxy-9-(4-hydroxyphenyl) nonanoic acid, tri-TMS & $\checkmark$ & $x$ & $\checkmark$ \\
\hline \multirow{10}{*}{ III } & 1 & Phenylacetic acid, TMS & $\checkmark$ & $\checkmark$ & $\checkmark$ \\
\hline & 2 & 1-(4-hydroxyphenyl)ethanone, TMS & $\checkmark$ & $x$ & $\checkmark$ \\
\hline & 3 & 4-Hydroxybenzoic acid, di-TMS & $\checkmark$ & $\checkmark$ & $\checkmark$ \\
\hline & 4 & 2-(4-Hydroxyphenyl)acetic acid, di-TMS & $\checkmark$ & $\checkmark$ & $\checkmark$ \\
\hline & 5 & 3-(4-Hydroxyphenyl)propanoic acid, di-TMS & $\checkmark$ & $x$ & $\checkmark$ \\
\hline & 8 & 4-(4-hydroxyphenyl)butanoic acid, di-TMS & $\checkmark$ & $x$ & $\checkmark$ \\
\hline & 10 & (2E)-3-(4-hydroxyphenyl)prop-2-enoic acid, di-TMS & $\checkmark$ & $x$ & $\checkmark$ \\
\hline & 12 & 5-(4-hydroxyphenyl)pentanoic acid, di-TMS & $\checkmark$ & $x$ & $\checkmark$ \\
\hline & 15 & 6-(4-hydroxyphenyl)hexanoic acid, di-TMS & $\checkmark$ & $x$ & $\checkmark$ \\
\hline & 32 & 9-(4-hydroxyphenyl)nonanoic acid, di-TMS & $\checkmark$ & $x$ & $\checkmark$ \\
\hline \multirow{2}{*}{ IV } & 6 & 3,4-Dihydroxybenzoic acid, tri-TMS & $\checkmark$ & $x$ & $\checkmark$ \\
\hline & 20 & 5-(3,4-dihydroxyphenyl)pentanoic acid, tri-TMS & $\checkmark$ & $x$ & $\checkmark$ \\
\hline
\end{tabular}

acids coupled with terminal carbon removal (group III). A similar situation occurred at $24 \mathrm{~h}$ of incubation, except that the kinetics of metabolites formation decreased in M. acridum and none of the groups of derivatives was distinguished in this strain, which seemed to be similar to $M$. globosum (Fig. 4C). In the PCA chart (Fig. 4), M. anisopliae was highly differentiated due to the high activity in the formation of metabolites belonging to groups I, III, and IV.

\subsection{Effect of 4-n-NP on CYP450 activity}

In all the tested strains, except in $M$. lepidiotae $(P>0.05)$, 4-nNP caused an increase in the activity of CYP450 in comparison to the respective biotic controls (Fig. 5). It was also observed that its activity in biotic controls differed slightly among the tested strains. $M$. brunneum and $M$. globosum exhibited the highest CYP450 activity in the samples supplemented with 4-nNP compared to appropriate controls without toxic substrate. The activity where 3.4 and 4.8 -fold respectively for $M$. brunneum and $M$. globosum $(P<0.05)$ (Fig. 5$)$. In other strains, except of $M$. lepidiotae, the activity of the tested protein in the samples supplemented with $4-n$-NP was at least doubled $(P<$ 0.05) (Fig. 5).

Numerous filamentous fungi are characterized by the presence of CYP450, which, due to its versatile catalytic properties, is involved in various metabolic processes, e.g., in the removal of xenobiotics (Durairaj et al., 2016). An example may be its participation in the elimination of dibutyltin (DBT) by the microscopic fungus $M$. robertsii (Siewiera et al., 2017), the elimination and detoxification of 2,4-dichlorophenoxyacetic acid (2,4-D) by the filamentous fungus $U$. isabellina (NykielSzymańska et al., 2018b), phenanthrene degradation by Pleurotus ostreatus (Bezalel et al., 1996) or by Cunninghamella elegans (Cerniglia and Yang, 1984), and its involvement in the transformation and detoxification of alachlor by Trichoderma koningii (Nykiel-Szymańska et al., 2018a). CYP450 monooxygenases have also been described in fungi belonging to the genus Metarhizium in terms of their contribution to the degradation and penetration of insect cuticle rich in alkanes and hydrocarbons, which is the first barrier in the protection against infection (Lin et al., 2011). Among the CYP450 genes, the family CYP52 occurs in Metarhizium sp. and is involved in the first hydroxylation stage in the process of assimilation of alkanes and the CYP53 clan, related to the metabolism and detoxification of aromatic hydrocarbons. According to the literature data, $M$. robertsii, as well as $M$. anisopliae, have two genes of both the CYP52 and CYP53 families (Huarte-Bonnet et al., 2017). In connection with the evidence for an increase in CYP450 activity in the cultures with the addition of 4-n-NP, an experiment to reveal the role of this enzyme during the process of xenobiotics degradation was carried out. The $M$. robertsii strain was selected as a research model, as a previous study has already confirmed CYP450 activity (Huarte-Bonnet et al., 2017). Moreover, our previous results (Różalska et al., 2015b) and also data obtained in this study indicate that $M$. robertsii underwent hydroxylation of 4-n-NP at many different positions within the first few hours of incubation, which suggests the participation of CYP450 in the degradation of 4-n-NP.

The results indicate that the role of the CYP is crucial for the initiation of degradation of 4-n-NP by M. robertsii. The addition of $A B T$ at $0 \mathrm{~h}$ of incubation inhibited the entire pathway (Tab. 2). Among the derivatives of 4-n-NP degradation, we paid special attention to the metabolites from groups I, III, and IV, because these were detected in samples at $6 \mathrm{~h}$ of incubation (Fig. 4, Fig. 3S). In the samples with the addition of ABT at $0 h$ of incubation, the presence of derivatives such as Phenylacetic acid, TMS (1); 4-Hydroxybenzoic acid, di-TMS (3); and 2-(4Hydroxyphenyl)acetic acid, di-TMS (4) was found, but most likely they were not products of xenobiotic decomposition, but were derived from fungal cells similar to what we had suggested in our previous work (Tab. 2) (Różalska et al., 2015b). The formation of metabolites was not inhibited when ABT was added after $6 \mathrm{~h}$ of incubation.

CYP450 is involved in the hydroxylation of 4-n-NP at the end of the aliphatic chain and also at the aromatic ring. This has been confirmed in salmon hepatic microsomes, where hydroxylation 
occurred at various positions and several CYP450 enzymes were involved in this process. The 9-(4Hydroxyphenyl)nonanoic acid, di-TMS as well as 8-(4Hydroxyphenyl)octanoic acid, di-TMS and 7-(4Hydroxyphenyl)heptanoic acid, di-TMS were identified as the main metabolites (Thibaut et al., 2002). Moreover, in the elimination of NP by human liver cells, CYP450 was involved in the process of hydroxylation at the $1^{\prime}$ carbon position, identifying the metabolite 4-(1-Hydroxynonyl)phenol, di-TMS (Deng et al., 2010). In transgenic tobacco cell cultures, CYP450 enzymes were involved in hydroxylation of 4-n-NP at the 4', 5', $6^{\prime}, 7^{\prime}$, and $8^{\prime}$ carbon positions of the aliphatic chain as well as in the hydroxylation of the aromatic ring (Berger et al., 2005).

\section{Conclusion}

The genus Metarhizium has the characteristic feature of the biodegradation of $4-n$-NP. For the first time, a xenobiotic degradation pathway, which is distinctive for this genus has been proposed. The pathway is complex and consists of four coexisting 4-n-NP degradation routes with versatile hydroxylations in the alkyl chain and in the aromatic ring. Moreover, the role of CYP450 in the elimination of 4-n-NP by $M$. robertsii has been confirmed.

\section{Acknowledgments}

This research was financed by a grant from the National Science Center in Krakow (Poland), contract number UMO2016/23/B/NZ9/00840.

\section{Appendix A. Supplementary data}

E-supplementary data of this work can be found in the online version of the paper.

\section{References}

Berger, A., Russ, A.S., Schuphan, I., Schmidt, B., 2005. Metabolism of 4-n-nonylphenol by non-modified and CYP1A1- and CYP1A2-transgenic cell cultures of tobacco. Z. Naturforsch. C. 60, 883-892. https://doi.org/10.1515/znc-2005-11-1211

Bezalel, L., Hadar, Y., Fu, P.P., Freeman, J.P., Cerniglia, C.E., 1996. Metabolism of phenanthrene by the white rot fungus Pleurotus ostreatus. Appl. Environ. Microbiol. 62, 25472553.

Cabana, H., Jones, P.J., Agathos, S.N., 2007. Elimination of endocrine disrupting chemicals using white rot fungi and their lignin modifying enzymes: A review. Eng. Life Sci. 7, 429-456. https://doi.org/10.1002/elsc.200700017

Cajthaml, T., 2014. Biodegradation of endocrine-disrupting compounds by ligninolytic fungi: mechanisms involved in the degradation. Environ. Microbiol. 17, 4822-4834. https://doi.org/10.1111/1462-2920.12460

Cerniglia, C.E., Yang, S.K., 1984. Stereoselective metabolism of anthracene and phenanthrene by the fungus
Cunninghamella elegans. Appl. Environ. Microbiol. 47, 119-24.

Chang, B.V., Chiang, B.W., Yuan, S.Y., 2007. Biodegradation of nonylphenol in soil. Chemosphere 66, 1857-1862. https://doi.org/10.1016/J.CHEMOSPHERE.2006.08.029

Corvini, P.F.X., Schäffer, A., Schlosser, D., 2006. Microbial degradation of nonylphenol and other alkylphenolsour evolving view. Appl. Microbiol. Biotechnol. 72, 223243. https://doi.org/10.1007/s00253-006-0476-5

Deng, P., Zhong, D., Nan, F., Liu, S., Li, D., Yuan, T., Chen, X., Zheng, J., 2010. Evidence for the bioactivation of 4nonylphenol to quinone methide and orthobenzoquinone metabolites in human liver microsomes. Chem. Res. Toxicol. 23, 1617-1628. https://doi.org/10.1021/tx100223h

Donato, M.T., Jiménez, N., Castell, J. V, Gómez-Lechón, M.J., 2004. Fluorescence-based assays for screening nine cytochrome P450 (P450) activities in intact cells expressing individual human P450 enzymes. Drug Metab. Dispos. 32, 699-706.

Durairaj, P., Hur, J.S., Yun, H., 2016. Versatile biocatalysis of fungal cytochrome P450 monooxygenases. Microb. Cell Fact. 15, 125. https://doi.org/10.1186/s12934-0160523-6

Huarte-Bonnet, C., Kumar, S., Saparrat, M.C.N., Girotti, J.R., Santana, M., Hallsworth, J.E., Pedrini, N., 2017. Insights into hydrocarbon assimilation by eurotialean and hypocrealean fungi: roles for CYP52 and CYP53 clans of cytochrome P450 genes. Appl. Biochem. Biotechnol. 184, 1047-1060. https://doi.org/10.1007/s12010-017-2608$\mathrm{z}$

Janicki, T., Długoński, J., Krupiński, M., 2018. Detoxification and simultaneous removal of phenolic xenobiotics and heavy metals with endocrine-disrupting activity by the nonligninolytic fungus Umbelopsis isabellina. J. Hazard. Mater. 360, 661-669. https://doi.org/10.1016/j.jhazmat.2018.08.047

Johnson, R.M., Mao, W., Pollock, H.S., Niu, G., Schuler, M.A., Berenbaum, M.R., 2012. Ecologically appropriate xenobiotics induce cytochrome P450s in Apis mellifera. PLoS One 7, e31051. https://doi.org/10.1371/journal.pone.0031051

Koumaki, E., Mamais, D., Noutsopoulos, C., 2018. Assessment of the environmental fate of endocrine disrupting chemicals in rivers. Sci. Total Environ. 628, 947-958. https://doi.org/10.1016/j.scitotenv.2018.02.110

Krupiński, M., Janicki, T., Pałecz, B., Długoński, J., 2014. Biodegradation and utilization of $4-n$-nonylphenol by Aspergillus versicolor as a sole carbon and energy source. J. Hazard. Mater. 280, 678-684. https://doi.org/10.1016/J.JHAZMAT.2014.08.060

Krupiński, M., Szewczyk, R., Długoński, J., 2013. Detoxification and elimination of xenoestrogen nonylphenol by the filamentous fungus Aspergillus versicolor. Int. Biodeterior. Biodegradation 82, 59-66. https://doi.org/10.1016/j.ibiod.2013.03.011 
Lin, L., Fang, W., Liao, X., Wang, F., Wei, D., St. Leger, R.J., 2011. The MrCYP52 cytochrome P450 monoxygenase gene of Metarhizium robertsii is important for utilizing insect epicuticular hydrocarbons. PLoS One 6, e28984. https://doi.org/10.1371/journal.pone.0028984

Liu, C., Lai, Y., Ouyang, J., Yang, T., Guo, Y., Yang, J., Huang, S., 2017. Influence of nonylphenol and octylphenol exposure on 5-HT, 5-HT transporter, and 5-HT2A receptor. Environ. Sci. Pollut. Res. Int. 24, 8279-8286. https://doi.org/10.1007/s11356-017-8487-6

Lovett, B., St. Leger, R.J., 2017. The insect pathogens. Microbiol. Spectr. 5 , 1-19. https://doi.org/10.1128/microbiolspec.FUNK-00012016

Nykiel-Szymańska, J., Bernat, P., Słaba, M., 2018a. Potential of Trichoderma koningii to eliminate alachlor in the presence of copper ions. Ecotoxicol. Environ. Saf. 162, 19. https://doi.org/10.1016/j.ecoenv.2018.06.060

Nykiel-Szymańska, J., Stolarek, P., Bernat, P., 2018b. Elimination and detoxification of 2,4-D by Umbelopsis isabellina with the involvement of cytochrome P450. Environ. Sci. Pollut. Res. 25, 2738-2743. https://doi.org/10.1007/s11356017-0571-4

Rajendran, R.K., Huang, S.L., Lin, C.C., Kirschner, R., 2016. Biodegradation of the endocrine disrupter 4-tertoctylphenol by the yeast strain Candida rugopelliculosa RRKY5 via phenolic ring hydroxylation and alkyl chain oxidation pathways. Bioresour. Technol. 226, 55-64. https://doi.org/10.1016/j.biortech.2016.11.129

Różalska, S., Bernat, P., Michnicki, P., Długoński, J., $2015 a$. Fungal transformation of $17 \alpha$-ethinylestradiol in the presence of various concentrations of sodium chloride. Int. Biodeterior. Biodegradation 103, 77-84. https://doi.org/10.1016/J.IBIOD.2015.04.016

Różalska, S., Soboń, A., Pawłowska, J., Wrzosek, M., Długoński, J., 2015b. Biodegradation of nonylphenol by a novel entomopathogenic Metarhizium robertsii strain. Bioresour. Technol. 191, 166-172. https://doi.org/10.1016/j.biortech.2015.05.011

Różalska, S., Szewczyk, R., Długoński, J., 2010. Biodegradation of 4-n-nonylphenol by the non-ligninolytic filamentous fungus Gliocephalotrichum simplex: A proposal of a metabolic pathway. J. Hazard. Mater. 180, 323-331. https://doi.org/10.1016/J.JHAZMAT.2010.04.034

Siewiera, P., Różalska, S., Bernat, P., 2017. Efficient dibutyltin (DBT) elimination by the microscopic fungus Metarhizium robertsii under conditions of intensive aeration and ascorbic acid supplementation. Environ. Sci. Pollut. Res. Int. 24, 12118-12127. https://doi.org/10.1007/s11356-017-8764-4

Szewczyk, R., Kuśmierska, A., Bernat, P., 2018. Ametryn removal by Metarhizium brunneum: Biodegradation pathway proposal and metabolic background revealed. Chemosphere 190, 174-183. https://doi.org/10.1016/J.CHEMOSPHERE.2017.10.011

Szewczyk, R., Soboń, A., Różalska, S., Dzitko, K., Waidelich, D.,
Długoński, J., 2014. Intracellular proteome expression during 4-n-nonylphenol biodegradation by the filamentous fungus Metarhizium robertsii. Int. Biodeterior. Biodegradation 93, 44-53. https://doi.org/10.1016/J.IBIOD.2014.04.026

Thibaut, R., Debrauwer, L., Perdu, E., Goks $\varnothing y r$, A., Cravedi, J.P., Arukwe, A., 2002. Regio-specific hydroxylation of nonylphenol and the involvement of CYP2K-and CYP2Mlike iso-enzymes in Atlantic salmon (Salmo salar). Aquat. Toxicol. 56, 177-90.

Vallini, G., Frassinetti, S., D’Andrea, F., Catelani, G., Agnolucci, M., 2001. Biodegradation of 4-(1-nonyl)phenol by axenic cultures of the yeast Candida aquaetextoris: identification of microbial breakdown products and proposal of a possible metabolic pathway. Int. Biodeterior. Biodegradation 47, 133-140. https://doi.org/10.1016/S0964-8305(01)00040-3

Yang, Z., Shi, Y., Zhang, Y., Cheng, Q., Li, X., Zhao, C., Zhang, D., 2018. Different pathways for 4-n-nonylphenol biodegradation by two Aspergillus strains derived from estuary sediment: Evidence from metabolites determination and key-gene identification. J. Hazard. Mater. 359, 203-212. https://doi.org/10.1016/j.jhazmat.2018.07.058

Zamaratskaia, G., Zlabek, V., 2009. EROD and MROD as markers of cytochrome P450 $1 \mathrm{~A}$ activities in hepatic microsomes from entire and castrated male pigs. Sensors 9, 21342147. https://doi.org/10.3390/s90302134

Zheng, G., Wang, T., Niu, M., Chen, X., Liu, C., Wang, Y., Chen, T., 2018. Biodegradation of nonylphenol during aerobic composting of sewage sludge under two intermittent aeration treatments in a full-scale plant. Environ. Pollut. 238, 783-791. https://doi.org/10.1016/J.ENVPOL.2018.03.112 


\section{Supplementary material}

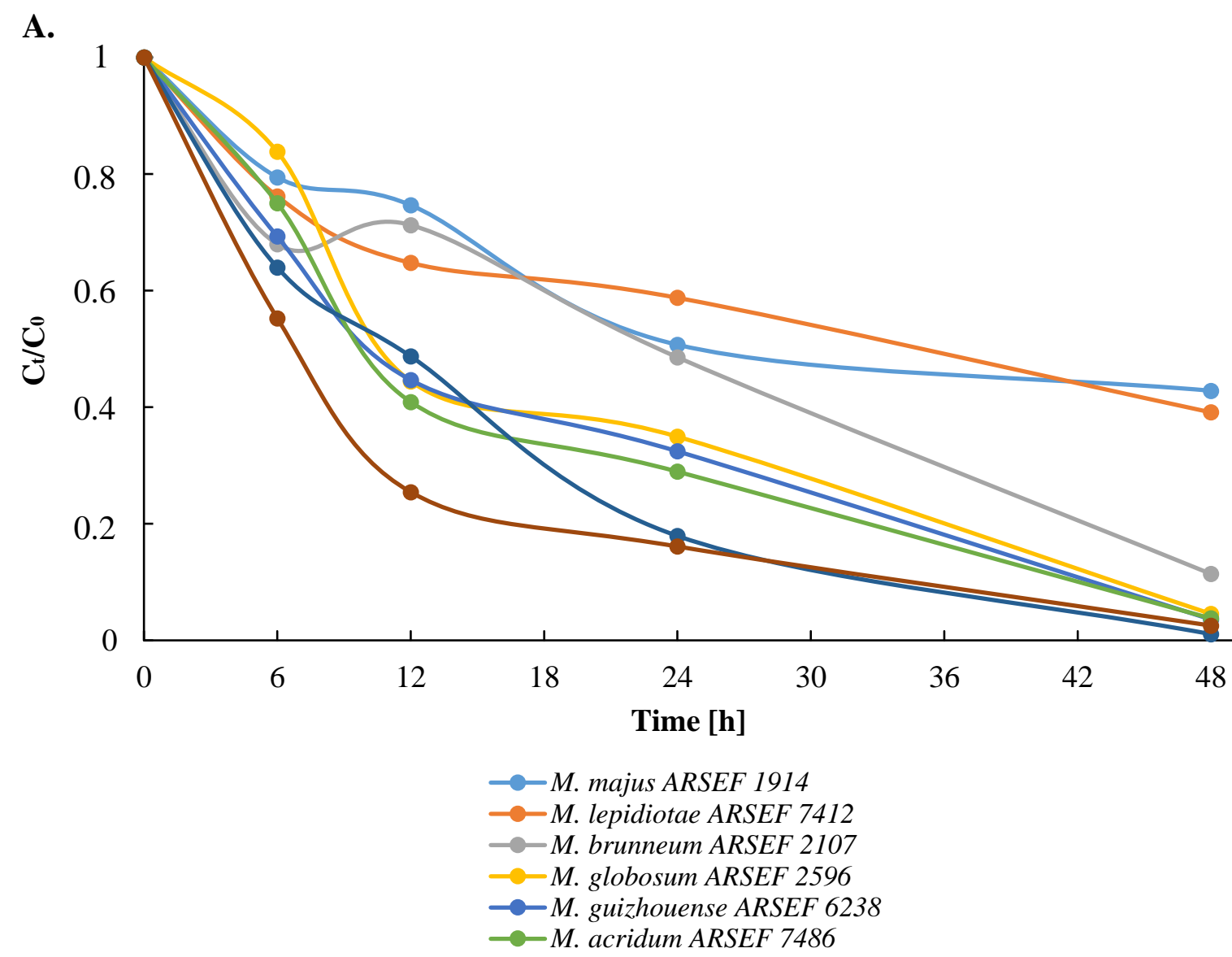

B.

\begin{tabular}{ccccc} 
& \multicolumn{4}{c}{ Rate constant $(\mathbf{k})$} \\
\cline { 2 - 5 } & $6 \mathrm{~h}$ & $12 \mathrm{~h}$ & $24 \mathrm{~h}$ & $48 \mathrm{~h}$ \\
\hline M. majus ARSEF 1914 & 0.038 & 0.049 & 0.028 & 0.035 \\
M. lepidiotae ARSEF 7412 & 0.045 & 0.072 & 0.022 & 0.039 \\
M. brunneum ARSEF 2107 & 0.064 & 0.057 & 0.030 & 0.090 \\
M. globosum ARSEF 2596 & 0.029 & 0.135 & 0.044 & 0.129 \\
M. guizhouense ARSEF 6238 & 0.061 & 0.134 & 0.047 & 0.139 \\
M. acridum ARSEF 7486 & 0.048 & 0.149 & 0.052 & 0.137 \\
M. anisopliae ARSEF 7487 & 0.075 & 0.120 & 0.072 & 0.189 \\
M. robertsii ARSEF 727 & 0.099 & 0.228 & 0.076 & 0.153
\end{tabular}

Figure 1S. Kinetics of degradation of 4-n-nonylphenol (4- $n$-NP) by Metarhizium sp.

A. Removal rate analysis $\mathrm{C}_{\mathrm{t}} / \mathrm{C}_{0}\left(\mathrm{C}_{\mathrm{t}}=\right.$ concentration at time $\mathrm{t} ; \mathrm{C}_{0}=$ initial concentration $)$;

B. Degradation rate constant (k). 


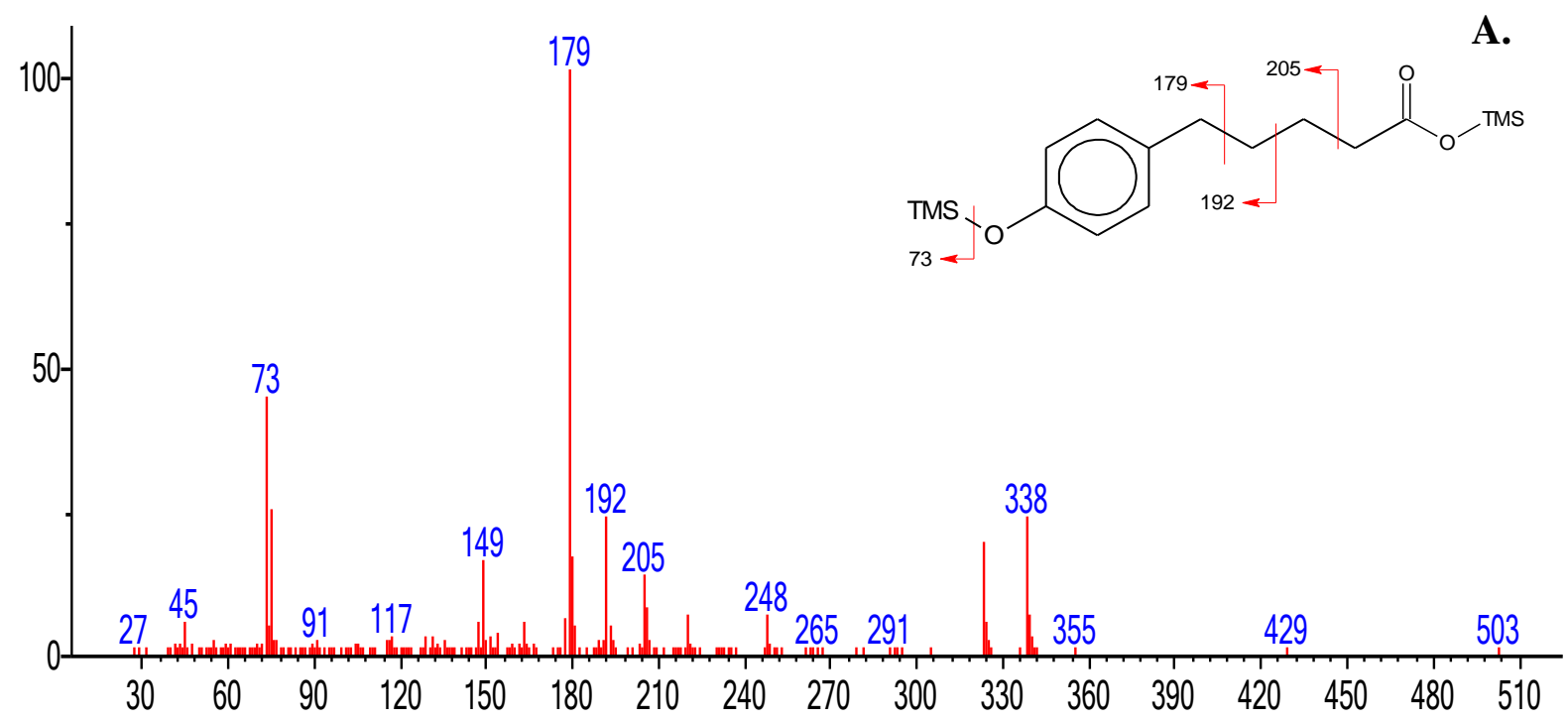

(Text File) Scan 1030 (11.464 min): 307.DI data.ms (-1026)

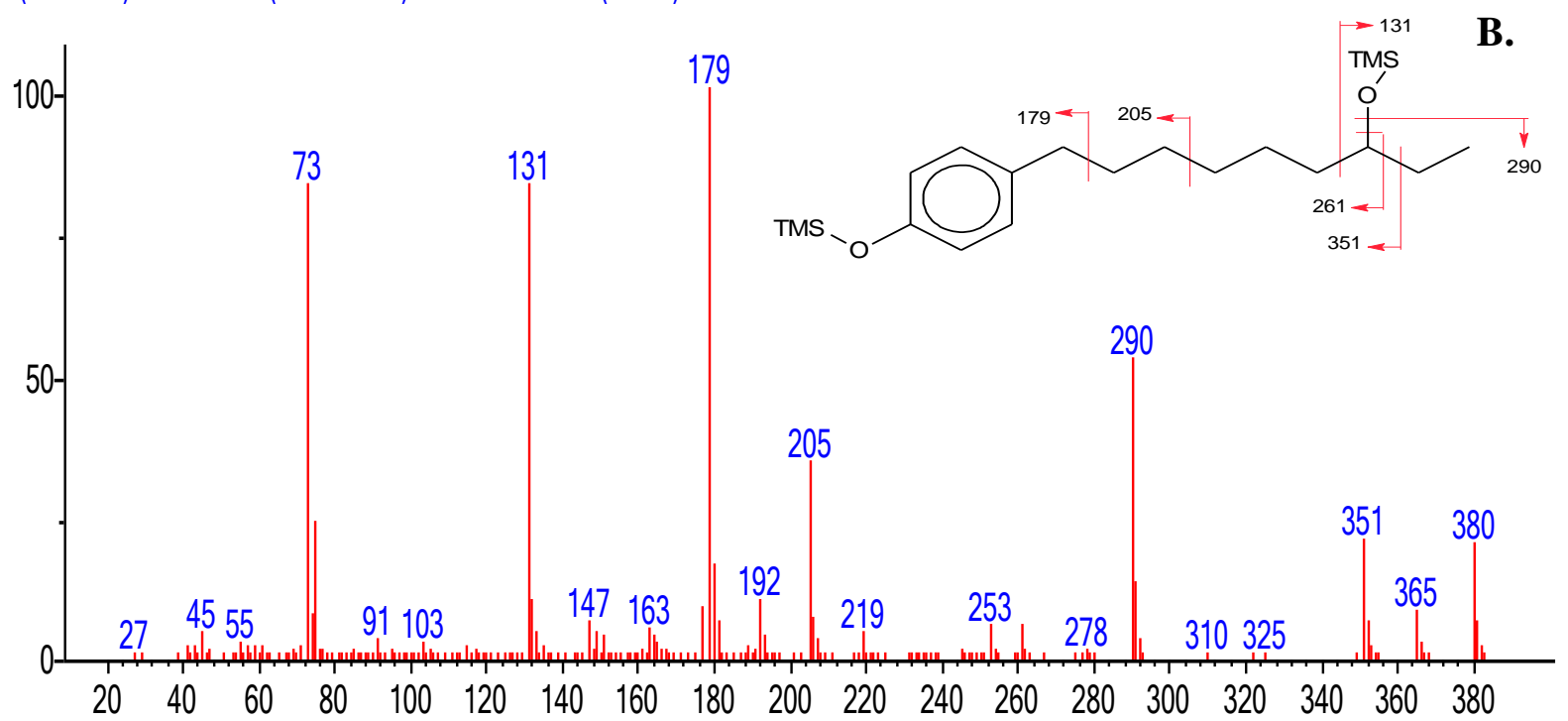

(Text File) Scan 1176 (12.509 min): 302.DI data.ms (-1170)
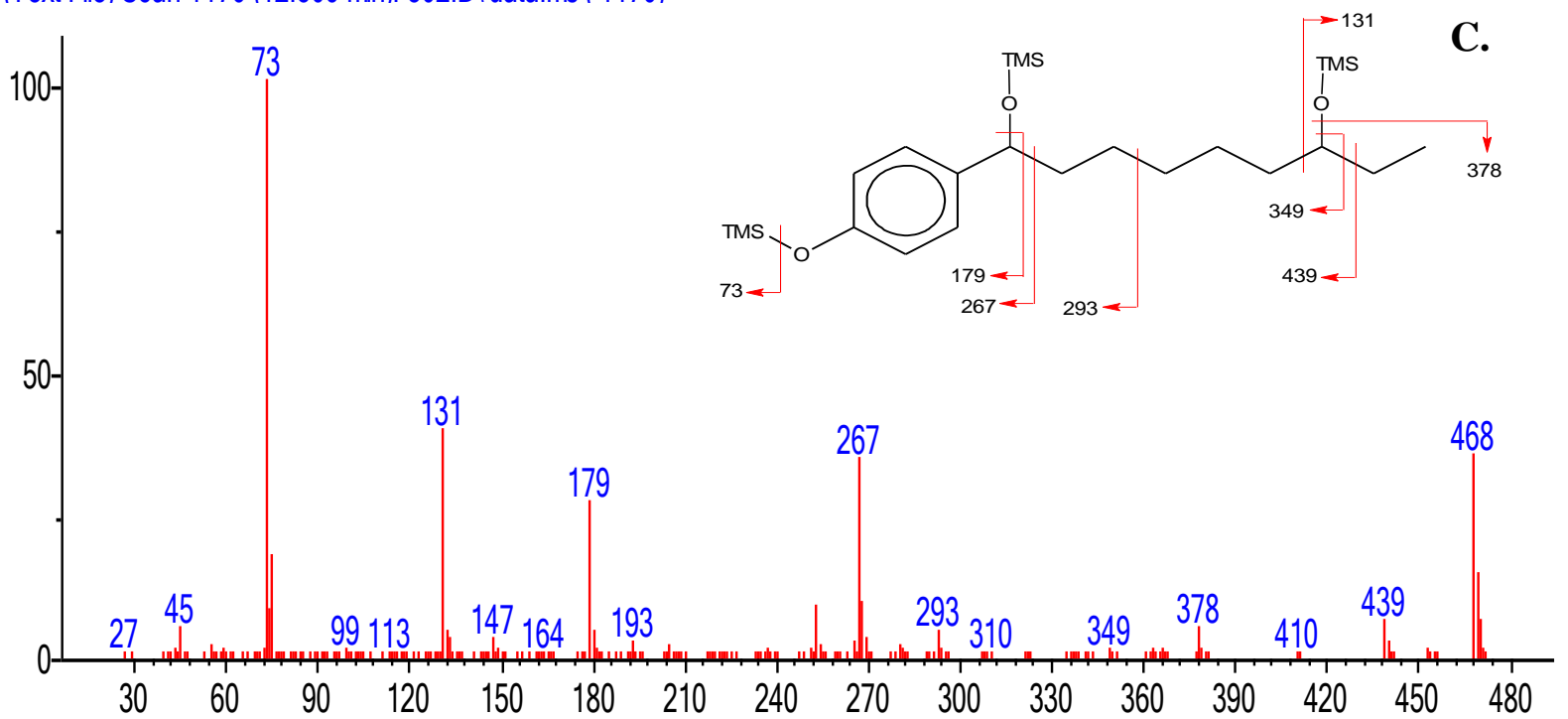

(Text File) Scan 1278 (13.240 min): 302.DI data.ms (-1275)

Figure 2S. Mass spectrum analysis of selected 4- $n$-NP intermediates. A. 4-(1-

Hydroxynonyl)phenol, di-TMS B. (4-Hydroxyphenyl)octanoic acid, di-TMS C. 9-Hydroxy-9(4-hydroxyphenyl)nonanoic acid, tri-TMS 

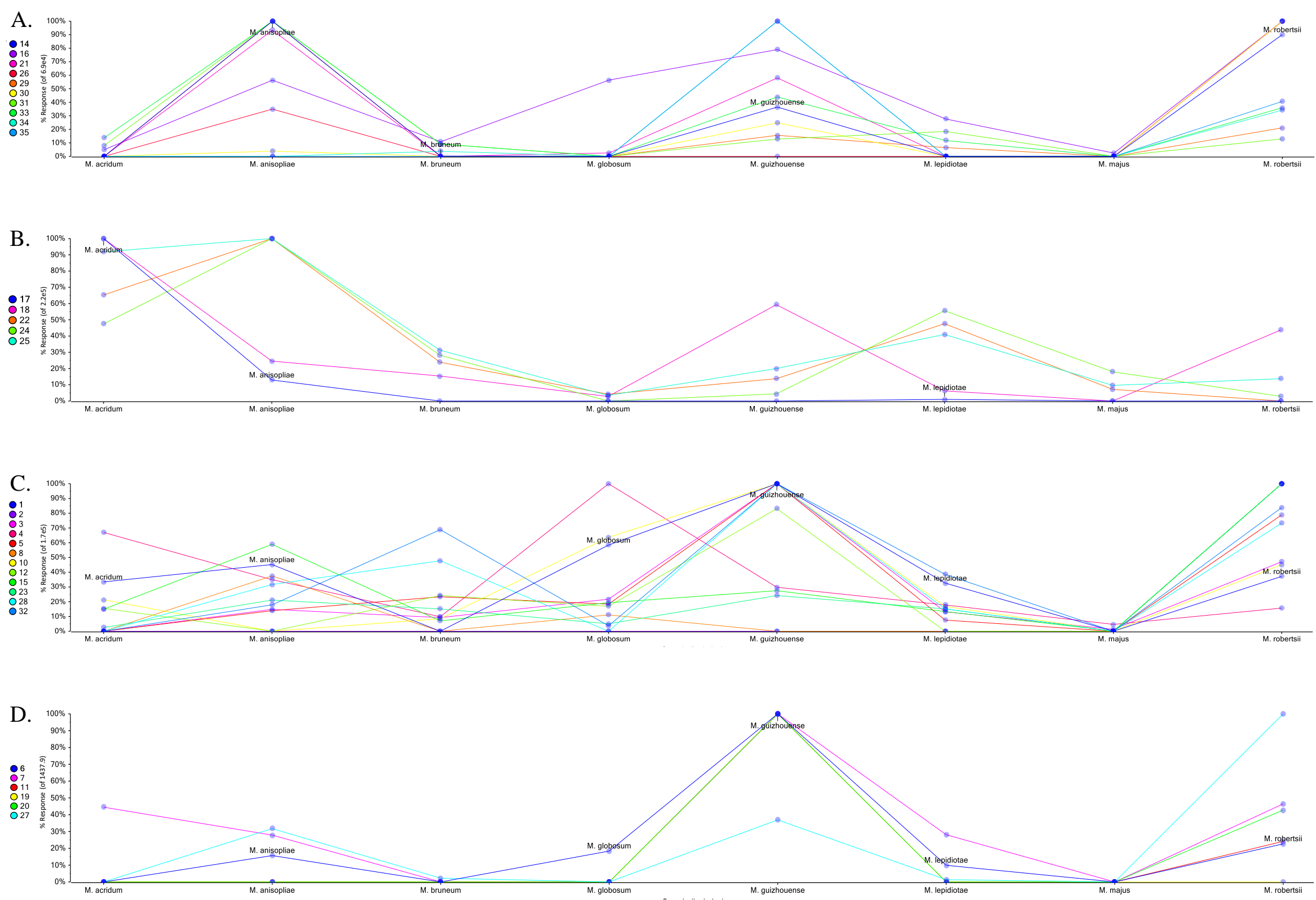

Figure 3S. Plots of peaks responses of four metabolites groups (A - group I, B-group II, C- group III, D - group IV) obtained from Metarhizium sp. cultures extracts after $6 \mathrm{~h}$ of incubation 

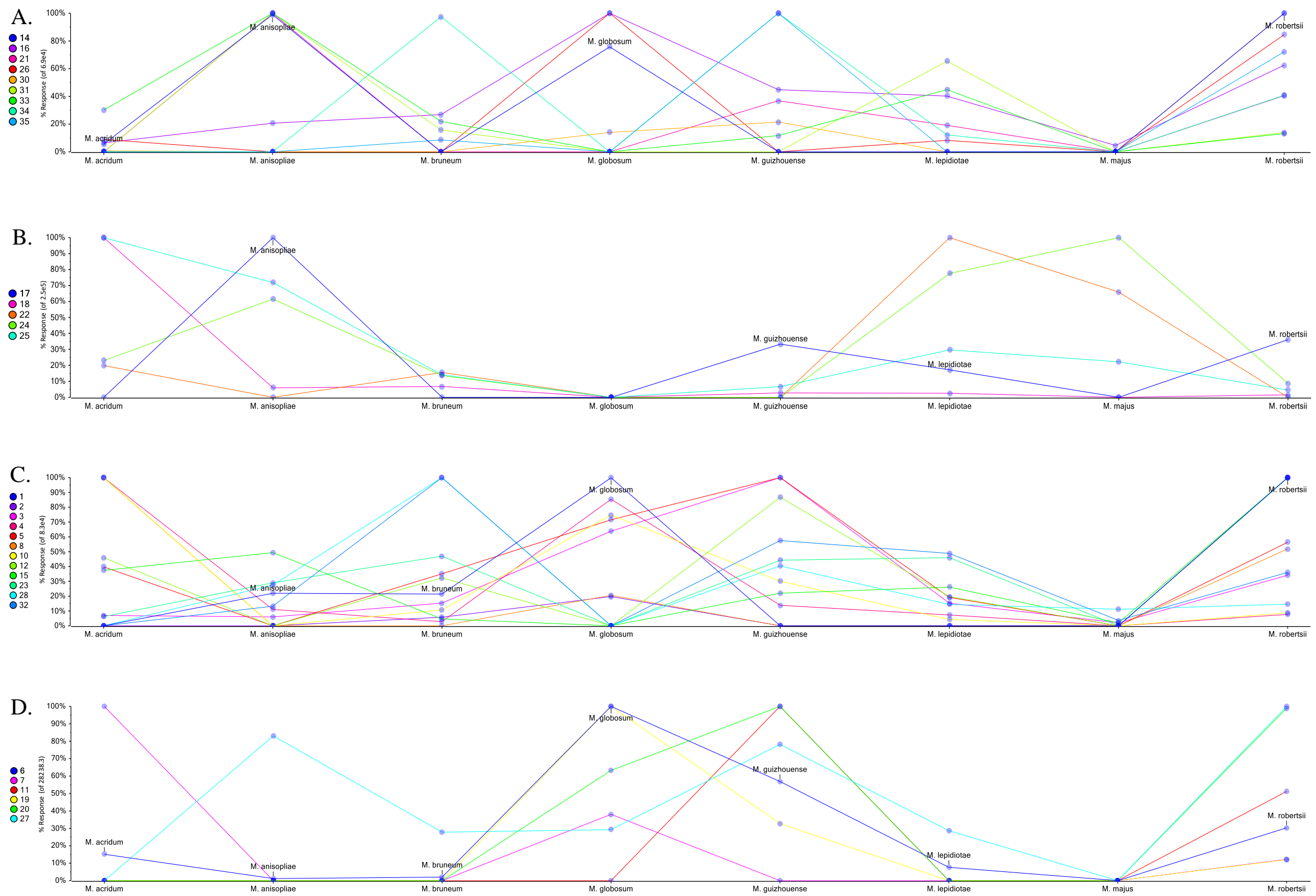

Figure 4S. Plots of peaks responses of four metabolites groups (A - group I, B- group II, C- group III, D - group IV) obtained from Metarhizium sp. cultures extracts after $12 \mathrm{~h}$ of incubation 

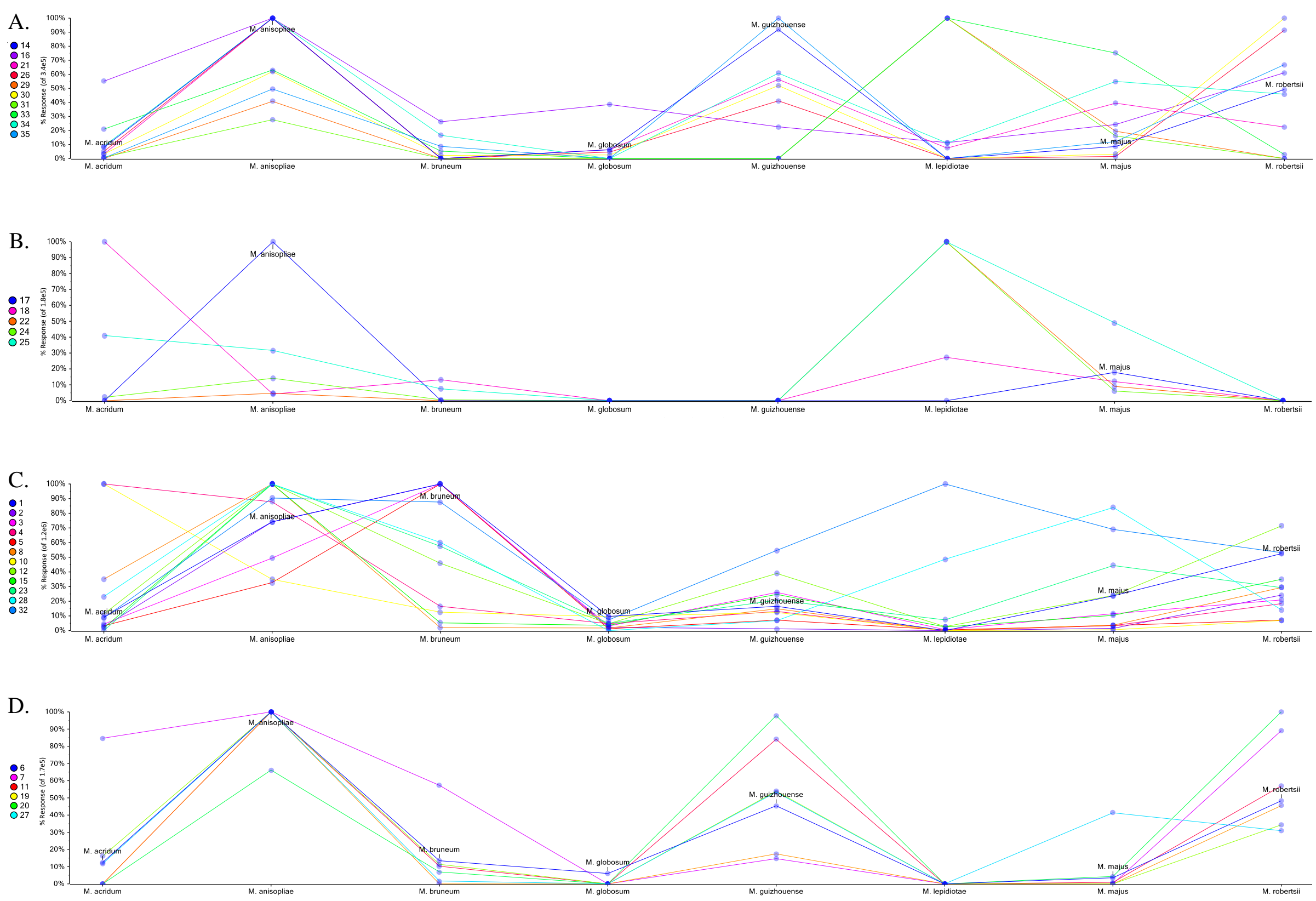

Figure 5S. Plots of peaks responses of four metabolites groups (A - group I , B- group II, C- group III, D - group IV) obtained from Metarhizium sp. cultures extracts after $24 \mathrm{~h}$ of incubation 